Article

\title{
Study of the Electrocatalytic Activity of Cerium Oxide and Gold-Studded Cerium Oxide Nanoparticles Using a Sonogel-Carbon Material as Supporting Electrode: Electroanalytical Study in Apple Juice for Babies
}

\section{Yahia M. Abdelrahim ${ }^{1}$, Stephen R. Benjamin ${ }^{1}$, Laura Ma Cubillana-Aguilera ${ }^{1}$, Ignacio Naranjo-Rodríguez ${ }^{1}$, José L. Hidalgo-Hidalgo de Cisneros ${ }^{1}$, Juan José Delgado ${ }^{2}$ and José $M^{a}$ Palacios-Santander ${ }^{1, *}$}

1 Departamento de Química Analítica, Facultad de Ciencias, Universidad de Cádiz, C/Republica Saharaui, S/N, 11510 Puerto Real, Cadiz, Spain;

E-Mails: yahia_sci@yahoo.com (M.Y.M.A.); steaje@gmail.com (S.R.B.);

laura.cubillana@uca.es (L.M.C.A.); ignacio.naranjo@uca.es (I.N.R.); jluis.hidalgo@uca.es (J.L.H.H.C.)

2 Departamento de Ciencia de los Materiales e Ingeniería Metalúrgica y Química Inorgánica, Facultad de Ciencias, Universidad de Cádiz, C/Republica Saharaui, S/N, 11510 Puerto Real, Cadiz, Spain; E-Mail: juanjose.delgado@uca.es

* Author to whom correspondence should be addressed; E-Mail: josem.palacios@uca.es;

Tel.: +34-956-01-6357; Fax: +34-956-01-6460.

Received: 28 February 2013; in revised form: 8 April 2013 / Accepted: 9 April 2013 /

Published: 12 April 2013

Abstract: The present work reports a study of the electrocatalytic activity of $\mathrm{CeO}_{2}$ nanoparticles and gold sononanoparticles (AuSNPs) $/ \mathrm{CeO}_{2}$ nanocomposite, deposited on the surface of a Sonogel-Carbon (SNGC) matrix used as supporting electrode and the application of the sensing devices built with them to the determination of ascorbic acid (AA) used as a benchmark analyte. Cyclic voltammetry (CV) and differential pulse voltammetry (DPV) were used to investigate the electrocatalytic behavior of $\mathrm{CeO}_{2}$ - and AuSNPs/ $/ \mathrm{CeO}_{2}$-modified SNGC electrodes, utilizing different concentrations of $\mathrm{CeO}_{2}$ nanoparticles and different AuSNPs: $\mathrm{CeO}_{2} \mathrm{w} / \mathrm{w}$ ratios. The best detection and quantification limits, obtained for $\mathrm{CeO}_{2}\left(10.0 \mathrm{mg} \cdot \mathrm{mL}^{-1}\right)$ - and $\mathrm{AuSNPs} / \mathrm{CeO}_{2}(3.25 \% \mathrm{w} / \mathrm{w})-$ modified SNGC electrodes, were $1.59 \times 10^{-6}$ and $5.32 \times 10^{-6} \mathrm{M}$, and $2.93 \times 10^{-6}$ and $9.77 \times 10^{-6} \mathrm{M}$, respectively, with reproducibility values of $5.78 \%$ and $6.24 \%$, respectively, for a linear concentration range from $1.5 \mu \mathrm{M}$ to $4.0 \mathrm{mM}$ of AA. The electrochemical devices were tested for the determination of AA in commercial apple juice for babies. The results were 
compared with those obtained by applying high performance liquid chromatography (HPLC) as a reference method. Recovery errors below 5\% were obtained in most cases, with standard deviations lower than $3 \%$ for all the modified SNGC electrodes. Bare, $\mathrm{CeO}_{2}$ - and $\mathrm{AuSNPs} / \mathrm{CeO}_{2}$-modified SNGC electrodes were structurally characterized using scanning electron microscopy (SEM) and energy dispersive X-ray spectroscopy (EDS). AuSNPs and AuSNPs $/ \mathrm{CeO}_{2}$ nanocomposite were characterized by UV-vis spectroscopy and X-ray diffraction (XRD), and information about their size distribution and shape was obtained by transmission electron microscopy (TEM). The advantages of employing $\mathrm{CeO}_{2}$ nanoparticles and AuSNPs $/ \mathrm{CeO}_{2}$ nanocomposite in SNGC supporting material are also described. This research suggests that the modified electrode can be a very promising voltammetric sensor for the determination of electroactive species of interest in real samples.

Keywords: cerium oxide nanoparticles; gold-studded cerium oxide nanoparticles; sonogel-carbon electrodes; ascorbic acid; structural characterization; electrochemistry; voltammetry; real sample; apple juice for babies

\section{Introduction}

Due to their chemical and physical properties, nanomaterials, and in particular nanoparticles, are the subject of intensive research nowadays because of their scientific and technological importance. Specifically, gold nanoparticles (AuNPs) are employed in many fields: biosensors, cosmetics, nanoelectronic, catalysis, semiconductors, and biomedicine, among others [1-5]. This great attention and interest in AuNPs is due to their good biological compatibility, excellent conducting capability and high surface-to-volume ratio [6]. Recently, gold sononanoparticles (AuSNPs) have been obtained through a new, fast, cheap and green synthetic method using high power ultrasound under ambient conditions [7,8]. The sonosynthesis of AuSNPs is based on the decomposition in less than 6 min and with very low-energy costs of the precursor (potassium tetrachloroaurate, $\mathrm{KAuCl}_{4}$ ) in aqueous solution and its subsequent reduction and stabilization by a proper agent (sodium citrate trihydrate), all favored by irradiation with high power ultrasound. This kind of nanomaterial has proved to offer good and interesting electrocatalytic properties versus AuNPs produced by classical synthesis methods [9].

Oxide-based materials have emerged as alternative electrode surfaces in a number of electrochemical applications. Most of the studies deal with their use in electrochemical synthesis, electro-remediation and fuel cells [10]. On the contrary, electroanalytical applications have been relatively poorly investigated so far [11-14]. Besides, metal oxides have demonstrated to possess anti-fouling properties [15], what make them very useful for the determination of analytes in real samples. According to this, metal oxides might be very useful to modify electrochemical (bio)sensors in order to determine different kind of chemical species such as inorganic as organic ones. The studies reported in literature normally involve the use of $\mathrm{Al}_{2} \mathrm{O}_{3}$ [16]; other oxides, such as $\mathrm{CeO}_{2}, \mathrm{WO}_{3}, \mathrm{TiO}_{2}$ (rutile) and $\mathrm{SnO}_{2}$ [11,17], have been more rarely employed.

Nanostructured $\mathrm{CeO}_{2}$ is an excellent electrode material since it is a nontoxic, chemically inert and size-dependent electrically conductive material [18]. Many of its multiple applications are related to its 
oxygen transfer and storage ability: electrochemical redox couple for mediator-less glucose sensor and control of automotive emissions [19]; electrolyte material [20]; and promotion of CO oxidation in direct alcohol fuel cells by supplying oxygen ions to the Pt catalyst [21-23], among others. Electrochemical (bio)sensors based on $\mathrm{CeO}_{2}$-nanostructured-modified electrodes with enhanced electrocatalytic activity may facilitate the determination of many biomolecules. For example, some analytes determined by using $\mathrm{CeO}_{2}$-nanostructured-modified electrodes are: uric acid [24], ascorbic acid (AA) [25] and their mixture [12] at modified glassy carbon electrodes, dopamine [26] at a based carbon fiber microbiosensor, and urea [27] at an indium tin oxide (ITO)-coated glass substrate. However, their analytical applications are not much extended despite of the good selectivity, sensitivity, reproducibility and stability obtained for many of these devices, what make them promising voltammetric sensors for real sample analysis. The reason for this fact is usually attributed to the poor electrical conductivity of the electrodes based on this metal oxide, which limits their applications.

To overcome this shortage, the formation of nanocomposites, where at least one of the constituents possesses remarkable conductivity, may be a solution to increase sensitivity. In the literature it is possible to find many examples of these nanocomposites: $\mathrm{Cu}$ nanoparticles/ $\mathrm{ZnO}$ [28], metal oxide/carbon nanotubes [29] and graphene/metal oxide core-shell nanostructures [30]. As far as we know there are only a few electroanalytical applications of similar $\mathrm{CeO}_{2}$-based nanostructures used as bi- or multi-functionalized electrocatalysts: $\mathrm{TiO}_{2} / \mathrm{CeO}_{2}$ nanoparticles [27] and $\mathrm{Pd}$ nanoparticles $/ \mathrm{CeO}_{2}$ nanoparticles [31].

The present work reports the study of the electrocatalytic activity of $\mathrm{CeO}_{2}$ nanoparticles and AuSNPs $/ \mathrm{CeO}_{2}$ nanocomposites. Both kinds of nanomaterials were deposited on the surface of a Sonogel-Carbon (SNGC) matrix by a simple drop-casting method and the sensing devices built with them were applied to the determination of AA, used as benchmark analyte. Different SNGC electrode configurations $\left(\mathrm{CeO}_{2}\right.$ concentration and $\mathrm{AuSNPs} / \mathrm{CeO}_{2}$ proportion used for the modification of the sensors) were tested. The advantages of employing $\mathrm{CeO}_{2}$ nanoparticles and $\mathrm{AuSNPs} / \mathrm{CeO}_{2}$ nanocomposites in SNGC supporting material are also described. The electrochemical performance of the sensors was characterized by Cyclic Voltammetry (CV) and Differential Pulse Voltammetry (DPV). Up to the extent of our knowledge, this is one of the first electrochemical applications of AuSNPs $/ \mathrm{CeO}_{2}$ nanocomposites as bi-functionalized electrocatalysts in (bio)sensors.

The electrochemical devices described in this paper were tested for the determination of AA in apple juice for babies, using High Performance Liquid Chromatography (HPLC) as a reference method. According to the type of real sample (apple juices for babies) in which the analyte is determined, the systems described in this work can be very promising tools for quality control purposes in food industry. It is noteworthy that this is the second time that exclusively electrochemical methods have been used to determine AA in commercial baby juices [9].

Finally, these devices were also structurally characterized by means of Scanning Electron Microscopy (SEM) and Energy Dispersive X-ray Spectroscopy (EDS). AuSNPs and AuSNPs/CeO 2 nanocomposite were characterized by UV-vis spectroscopy, X-Ray Diffraction (XRD) and Transmission Electron Microscopy (TEM). 


\section{Experimental Section}

\subsection{Reagents and Materials}

Methyltrimethoxysilane (MTMOS) was from Merck (Darmstad, Germany) and $\mathrm{HCl}$ was from Panreac (Barcelona, Spain). $\mathrm{KH}_{2} \mathrm{PO}_{4}$ and $\mathrm{K}_{2} \mathrm{HPO}_{4}$ for phosphate buffer solution (PBS) and potassium hexacyanoferrate(II) were from Fluka (Buchs, Switzerland). Sodium citrate trihydrate was purchased from Scharlau (Scharlab, Barcelona, Spain) and potassium tetrachloroaurate(III), ascorbic acid and nanopowder cerium(IV) oxide (99.95\%) form from Sigma-Aldrich (Sigma, Steinheim, Germany). Graphite powder natural, high purity-200 Mesh, 99.9999\% (metal basis), was from Alfa-Aesar (Johnson Matthey GmbH, Germany). All reagents were of analytical grade and used as received without further purification. Nanopure water was obtained by passing twice-distilled water through a Milli-Q system (18 M $\Omega \cdot \mathrm{cm}$, Millipore, Bedford, MA, USA). Glass capillary tubes, i.d. $1.15 \mathrm{~mm}$ $\left(\mathrm{A}=0.0415 \mathrm{~cm}^{2}\right)$, were used as the bodies of the composite electrodes. The nitrogen used for getting inert atmospheres and deaerating solutions in the measuring cell was $\mathrm{N}-55$ type.

\subsection{Instrumentation}

The synthesis of the SNGC material was carried out by sonicating with a high power SONICATOR 3000 ultrasonic generator from MISONIX Inc. (Farmingdale, NY, USA) equipped with a 13-mm titanium tip, that provides a maximum output power of $600 \mathrm{~W}$.

The voltammetric measurements were made on an Autolab® PGSTAT20 (Ecochemie, Utrecht, The Netherlands) potentiostat/galvanostat connected to a personal computer and a 663 Metrohm VA Stand module, using the software GPES (General Purpose Electrochemical System) 4.9 ver. for waveform generation, data acquisition and elaboration. The experiments were carried out in a single-compartment three-electrode cell, at room temperature $\left(25 \pm 1{ }^{\circ} \mathrm{C}\right)$. The counter electrode was a platinum wire, and a silver/silver chloride/3M KCl electrode was used as the reference. The composite-filled glass capillary tubes were used as the working electrode.

UV-Visible measurements were made with the Jasco 32 software using a Jasco V-550 (Easton, MD, USA) UV-visible spectrophotometer connected to a personal computer.

Scanning electron microscopy (SEM) studies were done on a QUANTA 200 (FEI Company, Hillsboro, OR, USA), normally operating at $20 \mathrm{keV}$ and equipped with a Microanalyzer (EDAX) to perform energy dispersive spectroscopy (EDS). Both secondary electron and backscattered electron detectors were used to take the micrographs.

Transmission electron microscopy (TEM) studies were carried out on a JEOL JEM-2010F (Jeol, Tokyo, Japan) microscope, equipped with a field emission gun, a scanning-transmission electron (STEM) module, a high angle annular dark field detector (HAADF) and an energy dispersive X-ray spectroscopy (EDS) microanalyzer. The microscope was operated at $200 \mathrm{kV}$ and in the STEM mode a $0.5 \mathrm{~nm}$ probe was used.

Finally, the X-ray diffraction pattern of dry $\mathrm{CeO}_{2}$ nanoparticles studded with AuSNPs at different $\mathrm{w} / \mathrm{w}$ ratios, evaporated at $50{ }^{\circ} \mathrm{C}$ and supported on an oriented-silicon crystal with no background signal, was obtained using a Bruker D8 Advance X-ray diffractometer with $\mathrm{Cu} \mathrm{K} \alpha$ radiation $(\lambda=0.1542 \mathrm{~nm})$. Intensities were measured between $35^{\circ}$ and $40^{\circ}(2 \theta$ values $)$ at intervals of $0.020^{\circ}$. 
The results obtained by the electroanalytical techniques were compared with those obtained by HPLC, taken as a reference method. A JASCO HPLC system with UV detection and a Gemini C18 $(250 \mathrm{~mm} \times 3.0 \mathrm{~mm}) 5 \mu \mathrm{m}$ particle size column was used to carry out the measurements. The analytical flow rate was $0.8 \mathrm{~mL} \cdot \mathrm{min}^{-1}$. As solvent a mixture of water $-0.1 \%$ formic acid $(\mathrm{v} / \mathrm{v})$ was used. Detection wavelength was set at $\lambda=245 \mathrm{~nm}$.

\subsection{Sonogel-Carbon Electrode Preparation Procedure}

To prepare the SNGC electrodes, the procedures described in literature were used [32]. Several minutes after beginning the gelification process of the sonosol, the capillary tubes were filled with the synthesized material to obtain the electrode as described elsewhere [33].

\subsection{Electrochemical Pre-Treatment of Sonogel-Carbon Electrodes}

Prior to the deposition of $\mathrm{CeO}_{2}$ or AuSNPs/CeO $/ \mathrm{C}_{2}$ nanoparticles on the surface of the SNGC electrodes, they were electrochemically pre-treated by dipping them in $0.05 \mathrm{M}$ sulphuric acid solution in the electrochemical cell, the SNGC electrodes operating as working electrode. The electrodes were polarized in $\mathrm{CV}$ from -0.5 to $+1.5 \mathrm{~V}$ for 5 scans at a scan rate of $0.05 \mathrm{~V}\left(50 \mathrm{mV} \cdot \mathrm{s}^{-1}\right)$. Electrodes with similar current backgrounds were selected, carefully washed with Milli-Q water and dried at room temperature.

\subsection{Synthesis of gold sononanoparticles (AuSNPS)}

AuSNPs were synthesized as described in [7,8]. All the glass material used for the synthesis was cleaned with aqua regia $\left(1: 3 \mathrm{v} / \mathrm{v} \mathrm{HNO}_{3}-\mathrm{HCl}\right)$ solution and then thoroughly rinsed with Milli-Q water prior to use. In general, gold nanoparticles show a characteristic surface plasmon band between 520 and $550 \mathrm{~nm}$; hence, the formation of AuSNPs was monitored by using UV-visible spectrophotometry. After the synthesis, colloidal gold solution was stored in darkness conditions at $4{ }^{\circ} \mathrm{C}$ prior to use.

\subsection{Preparation of $\mathrm{CeO}_{2}$ and $\mathrm{AuSNPs} / \mathrm{CeO}_{2}$ Nanoparticle Solutions}

On the one hand, several solutions of $\mathrm{CeO}_{2}$ nanoparticles at different concentrations $(0.25,0.5$, $0.75,1.0,2.5,5.0,7.5$ and $10.0 \mathrm{mg} \cdot \mathrm{mL}^{-1}$ ) were prepared by dissolving a suitable amount of $\mathrm{CeO}_{2}$ nanoparticles in a certain volume of Milli-Q water.

On the other hand, six solutions mixing $\mathrm{CeO}_{2}$ nanoparticles and AuSNPs at different percentages $\left(2.5 \%, 3.25 \%, 5 \%, 12.5 \%, 17.25 \%\right.$ and $25 \% \mathrm{w} / \mathrm{w}$ AuSNPs: $\left.\mathrm{CeO}_{2}\right)$ were prepared by addition of the proper amount of $\mathrm{CeO}_{2}$ nanoparticles to the AuSNPs solution, prepared by ultrasonic synthesis, in order to obtain the desired proportions. Then, the six mixture solutions were stirred vigorously on a magnetic stirring hot-plate around $8 \mathrm{~h}$. For TEM and DRX characterization, the solutions were centrifuged with a CENCOM 2 angular centrifuge to separate the $\mathrm{CeO}_{2}$ nanoparticles studded with AuSNPs, and afterwards, the precipitate was dried in a furnace at $50{ }^{\circ} \mathrm{C}$ for $24 \mathrm{~h}$. 


\subsection{Preparation of the $\mathrm{CeO}_{2}$ and $\mathrm{AuSNPS} / \mathrm{CeO}_{2}$ nanoparticle-modified $\mathrm{SNGC}$ sensors}

$\mathrm{CeO}_{2}$ nanoparticles or $\mathrm{AuSNPs} / \mathrm{CeO}_{2}$ nanocomposite solutions prepared as described above $(3 \mu \mathrm{L})$, were deposited on the SNGC electrode surface and allowed to dry at room temperature in the darkness for 24 hours. After the drying, the electrodes were stored at $4{ }^{\circ} \mathrm{C}$ in darkness before and after their use. By following this process, the $\mathrm{CeO}_{2}$ and AuSNPs $/ \mathrm{CeO}_{2}$ nanoparticles were well adhered to the surface of the electrodes.

\subsection{Experimental Procedure}

The experimental procedure can be described as follows: $25 \mathrm{~mL}$ of $0.2 \mathrm{M}$ PBS buffer (supporting electrolyte, $\mathrm{pH}$ 6.9) were poured in the electrochemical cell placed in the Metrohm VA 663 Stand. After passing $\mathrm{N}_{2}$ for at least $15 \mathrm{~min}$ through the solution in order to deaerate it, the signal corresponding to the background was recorded three times, passing $\mathrm{N}_{2}$ for 1 min between two different sweeps. Next, the adequate amount of analyte was added into the cell to carry out the measurement step under the same conditions as the background.

The instrumental parameters for $\mathrm{CV}$ sweeps were as follows: potential range from -0.5 to +1.0 or $-1.2 \mathrm{~V}$; scan rates: from 5 to $200 \mathrm{mV} \cdot \mathrm{s}^{-1}$. In the case of DPV, the optimal instrumental parameters were as follows: potential range from 0.5 to $+0.7 \mathrm{~V}$; modulation time: $0.05 \mathrm{~s}$; interval time: $0.4 \mathrm{~s}$; scan rate: $50 \mathrm{mV} \cdot \mathrm{s}^{-1}$; step potential: $16 \mathrm{mV}$; and pulse amplitude: $100 \mathrm{mV}$.

In order to determine the concentration of ascorbic acid in real samples, the procedure was as follows: $1 \mathrm{~mL}$ of the commercial apple juice from local source (labeled concentration $=25 \mathrm{mg} / 100 \mathrm{~mL}=$ $250 \mathrm{mg} \cdot \mathrm{L}^{-1}$ as average value) were diluted with phosphate buffer solution $(0.2 \mathrm{M}, \mathrm{pH}=6.90)$ until obtaining a final volume of $25 \mathrm{~mL}$ in an electrochemical cell, and then the electrode system was immersed into the solution. The electrochemical measurements were carried out under optimized DPV conditions, using the standard addition method.

Juice samples to be injected into the HPLC were prepared as follows: the real sample was diluted in sonicated Milli-Q water in 1:200 molar ratio. After measuring the real sample, different standard additions of AA in the range from 0.05 to $5 \mathrm{mg} \cdot \mathrm{L}^{-1}$ with increments of $0.5 \mathrm{mg} \cdot \mathrm{L}^{-1}$ each time were carried out.

\section{Results and Discussion}

\subsection{Structural Characterization of AuSNPs and AuSNPS/CeO $\mathrm{O}_{2}$ Nanoparticles}

AuSNPs and AuSNPS/ $\mathrm{CeO}_{2}$ nanoparticles were characterized by XRD and information about their size distribution and shape was obtained using the TEM technique.

\subsubsection{Transmission Electron Microscopy}

The morphology, shape and size distribution of AuSNPs were studied by TEM. As it can be clearly seen in Figure 1(A), AuSNPs are spherical-shaped and well dispersed from each other, with almost no aggregates (the rectangular and cubic forms correspond to $\mathrm{CeO}_{2}$ nanoparticles). Moreover, the size is very homogeneous following a Gaussian distribution, with a size distribution between 4 and $10 \mathrm{~nm}$ (Figure 1(D)). It should be pointed out that the particle size distribution was obtained using 
HAADF-STEM images in combination with elemental analysis by EDS to ensure a reliable particle size distribution. The $85 \%$ of the AuSNPs shows a diameter ranking from 5 to $8 \mathrm{~nm}$. The average size is $7.1 \pm 1.3 \mathrm{~nm}$.

Figure 1. Typical HAADF-STEM (A) and HREM (B) micrograph of the sample. Digital Diffraction Pattern of selected areas $(\mathbf{C})$ in image $B$ and the particle size distribution (D) are included.

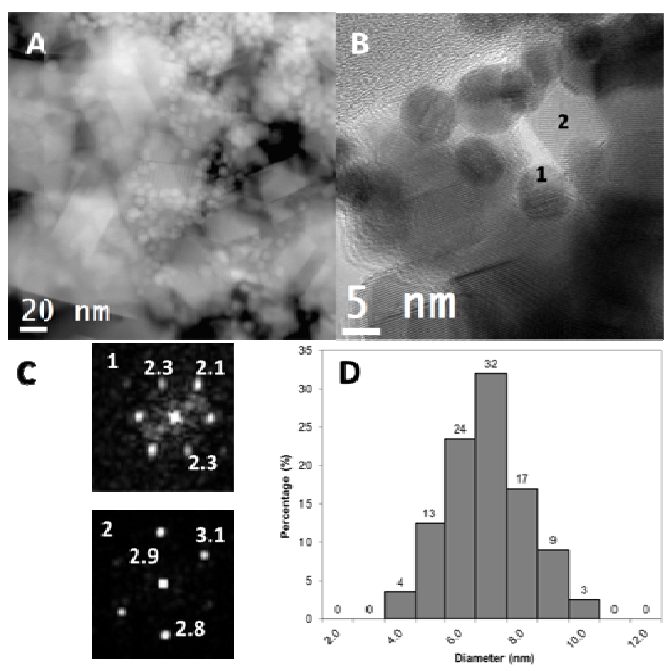

Regarding $\mathrm{CeO}_{2}$ nanoparticles studded with AuSNPs, Figure 1(A,B) show that the AuSNPs are completely distributed and dispersed over the $\mathrm{CeO}_{2}$ nanoparticles, which possess a heterogeneous morphology and an average size in the $30-50 \mathrm{~nm}$ range, in agreement with the reagent label. Besides, it seems that there is a good interaction between both kinds of nanoparticles. It must be taken into account that the AuSNPs/ $\mathrm{CeO}_{2}$ nanoparticles were obtained by simply putting both nanomaterials in contact in solution, favored by the stirring process, with no calcination; hence, no more than physisorption-based interactions might be presumed between them, although the micrographs may point stronger links, even at the level of the crystalline structure itself. The deposition method employed to fix the sample to the grid was a simple drop-casting process, the same used for the deposition of this nanocomposite on the electrodes surface. The information retrieved from the Digital Diffraction Patterns (DDP) serve to corroborate the composition of the nanoparticles. As example, Figure 1(C) shows two typical DDP of a gold (1) and a ceria (2) nanoparticles, both of them recorded along the [011] zone axis in the [011].

\subsubsection{X-ray Diffraction}

The crystalline nature of AuSNPs and $\mathrm{CeO}_{2}$ was further confirmed from X-ray diffraction analysis. Because of the small size of the AuSNPs, the diffraction peaks were neither as intense nor as narrow as those observed for $\mathrm{CeO}_{2}$. As shown in Figure 2, the presence of four weak and broad peaks at $38.3^{\circ}$,

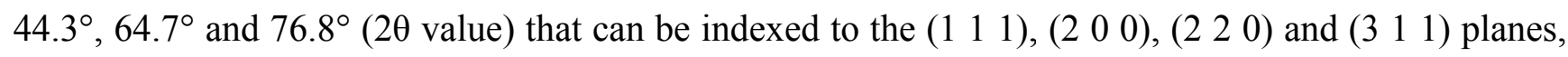
respectively corresponding to a face-centered cubic (fcc) phase of metallic gold, according to JCPDS No.04-0784. Concerning the $\mathrm{CeO}_{2}$ crystals, diffractogram shows three intense and narrow peaks at $28.6^{\circ}, 47.6^{\circ}$ and $56.4^{\circ}$ ( $2 \theta$ value) that can be indexed to the $\left(\begin{array}{lll}1 & 1 & 1\end{array}\right),\left(\begin{array}{lll}2 & 2 & 0\end{array}\right)$ and $\left(\begin{array}{lll}3 & 1 & 1\end{array}\right)$ planes, 
respectively corresponding to a cubic ceria fluorite (Fm3m) phase of $\mathrm{CeO}_{2}$, according to JCPDS No. 43-1002. Other less intense peaks can also be indexed for the same crystalline structure: $33.2^{\circ}$ and $59.2^{\circ}$ for $\left(\begin{array}{lll}2 & 0 & 0\end{array}\right)$ and $\left(\begin{array}{lll}1 & 1 & 2\end{array}\right)$ planes, respectively.

Figure 2. XRD pattern of $\mathrm{AuSNPs} / \mathrm{CeO}_{2}$ nanoparticles.

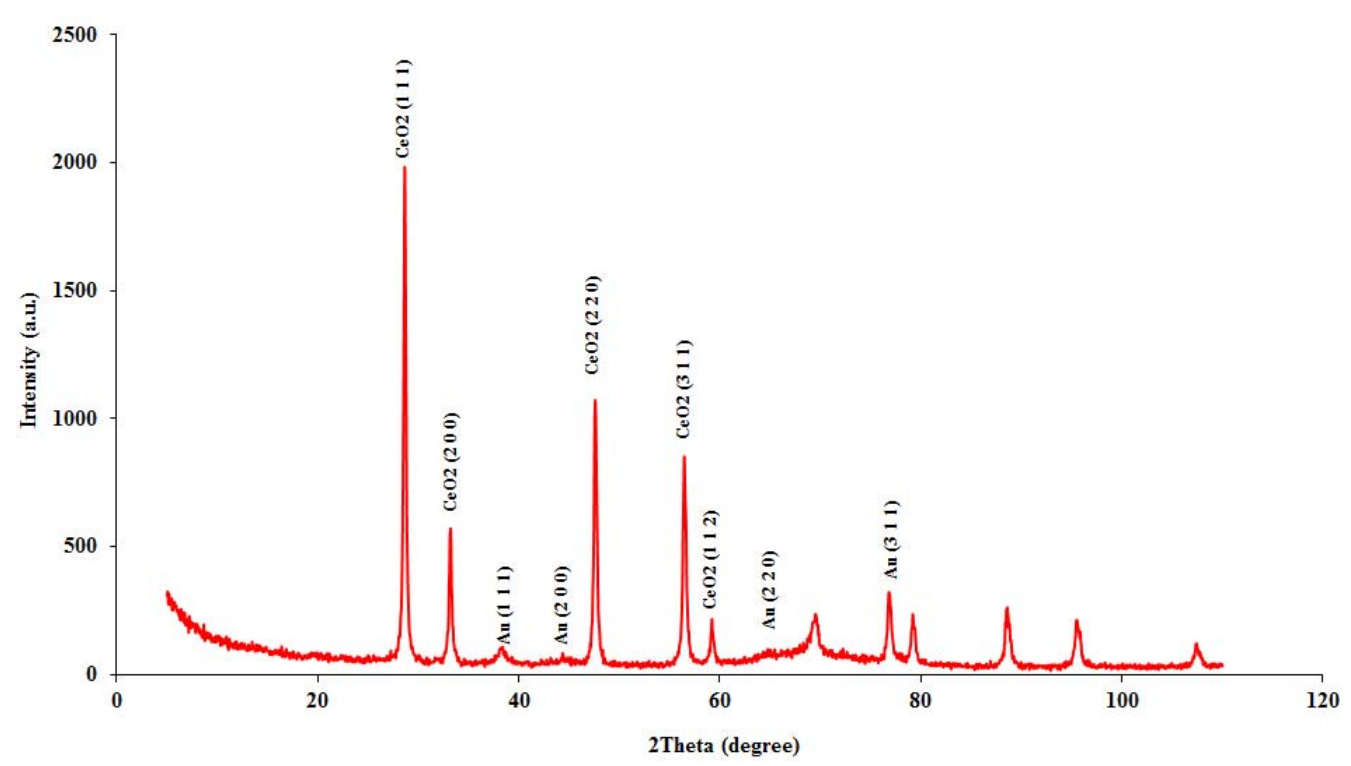

From the peak widths corresponding to $\mathrm{CeO}_{2}$, an average particle diameter, $\overline{\mathrm{D}}$, of $30.2 \pm 3.0 \mathrm{~nm}$ was obtained according to Scherrer equation:

$$
D=\frac{0.9 \cdot \lambda}{\beta \cdot \cos \theta}
$$

where 0.9 is the shape factor, $\lambda$ is the wavelength corresponding to the $\mathrm{Cu} K \alpha$ radiation $(0.154060 \mathrm{~nm})$, $\theta$ is the reflection angle, and $\beta$ is the line broadening (peak width) at half the maximum. The results are coherent with the reagent label $(\overline{\mathrm{D}}<50 \mathrm{~nm})$.

\subsubsection{UV-Visible Spectroscopy Studies}

It is well established that UV-visible spectroscopy is a very effective technique to monitor the evolution of metal species in the synthesis of metal nanoparticles [34,35]. Thus, in our case, the formation of AuSNPs was followed by measuring, at room temperature, the absorbance of the ruby red color colloidal solution containing gold nanoparticles in the range 200-800 nm. The reduction of $\mathrm{Au}^{3+}$ to $\mathrm{Au}^{0}$ showed a maximum of absorption at $525 \mathrm{~nm}$, indicating the production of the surface plasmon resonance effect, typical of the AuSNPs. Apart from being stable for more than one month, AuSNPs were also well dispersed in solution and with minimal aggregation [9].

UV-visible spectroscopy was also used to study the formation of the AuSNPs/ $\mathrm{CeO}_{2}$ nanocomposite in solution at the six different w/w ratios. According to the Experimental Section, after $8 \mathrm{~h}$ of stirring, the different AuSNPs $/ \mathrm{CeO}_{2}$ solutions were centrifuged. Later, the supernatants were collected and its absorbance spectra were recorded in the range 200-800 $\mathrm{nm}$ and at room temperature and at different stirring time, in order to know whether all the AuSNPs present in the original solutions were linked in some way to the $\mathrm{CeO}_{2}$ nanoparticles and what time of contact was necessary. 
Figure 3. UV-visible spectra recorded for $\mathrm{AuSNPs} / \mathrm{CeO}_{2}(5 \% \mathrm{w} / \mathrm{w})$ nanoparticles at different stirring times: (a) AuSNPs spectrum immediately after the synthesis; AuSNPs $/ \mathrm{CeO}_{2}$ nanoparticles spectra after stirring (b) $15 \mathrm{~min}$; (c) $30 \mathrm{~min}$; (d) $45 \mathrm{~min}$; (e) $1 \mathrm{~h}$; (f) $2 \mathrm{~h}$; (g) $8 \mathrm{~h}$ and (h) $10 \mathrm{~h}$.

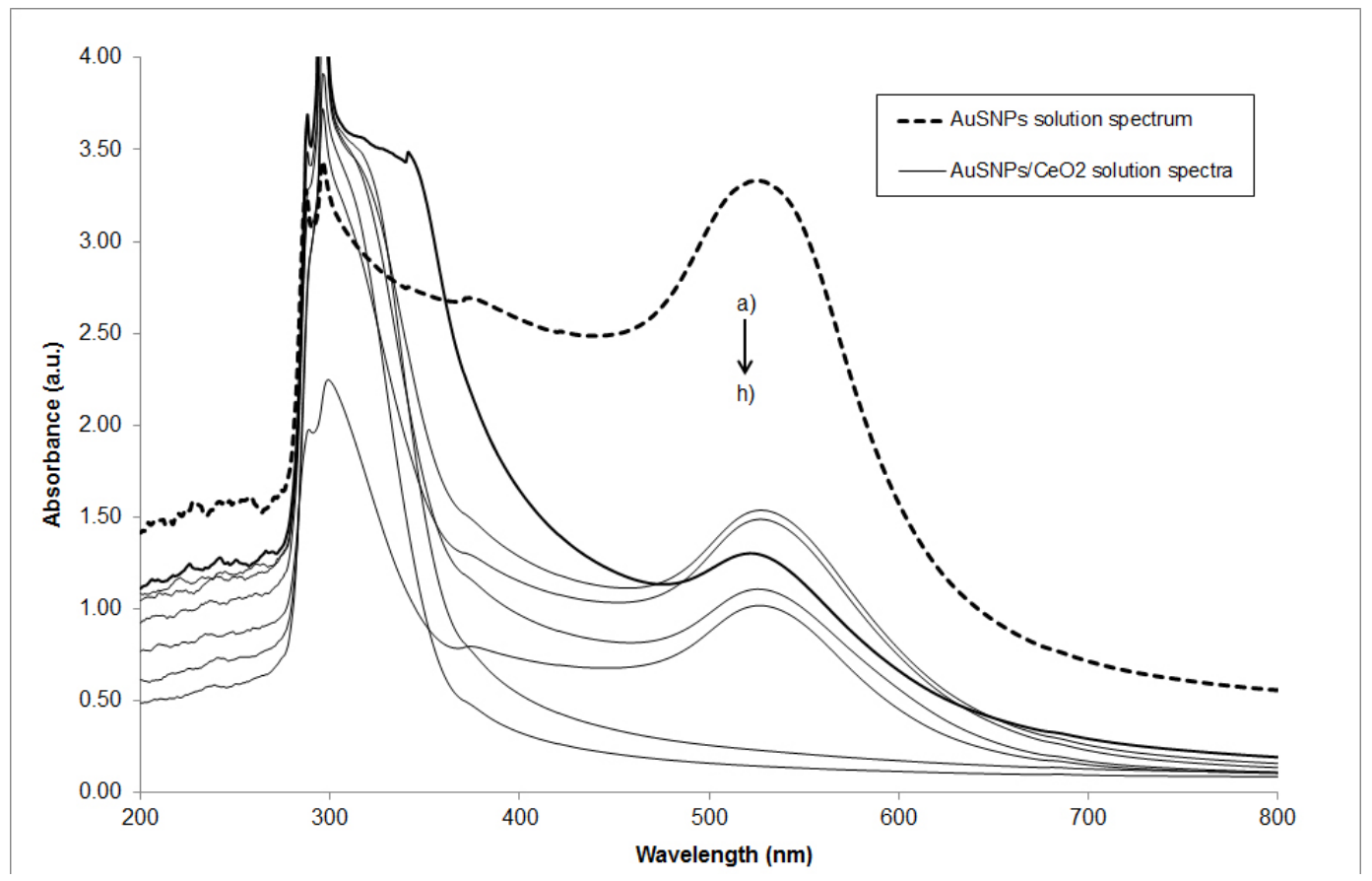

Figure 3 shows several UV-visible absorption spectra for the AuSNPs/ $\mathrm{CeO}_{2}$ nanoparticles at different stirring times. From the figure, we can conclude that the decoration of $\mathrm{CeO}_{2}$ nanoparticles with AuSNPs affects the absorption peaks of AuSNPs and it depends significantly on the stirring time. On one hand, it is obvious that an increase in the stirring time leads to an increased probability of contact between the AuSNPs and $\mathrm{CeO}_{2}$ nanoparticles; thus the ability to form the AuSNPs/CeO 2 nanocomposite is enhanced. As it can be seen, when increasing the stirring time, the absorption bands of AuSNPs observed at $525 \mathrm{~nm}$ begin to decrease until they disappear completely after $8-10 \mathrm{~h}$ of stirring. That is why the value of $8 \mathrm{~h}$ was chosen as an appropriate contact time to prepare the AuSNPs $/ \mathrm{CeO}_{2}$ nanocomposite solutions, since after this time no plasmon resonance absorption peak corresponding to free AuSNPs was observed. This selected value was also independent of the AuSNPs: $\mathrm{CeO}_{2} \mathrm{w} / \mathrm{w}$ proportion of the nanocomposite obtained.

\subsection{Electrochemical Characterization}

The electrochemical characterization of the unmodified, $\mathrm{CeO}_{2}$-modified and $\mathrm{AuSNPs} / \mathrm{CeO}_{2}$-modified SNGC electrodes was conducted with two electroanalytical techniques: cyclic voltammetry (CV) and differential pulse voltammetry (DPV). In order to do that, fifteen electrodes with different configurations were tested: a bare or unmodified SNGC electrode, eight different $\mathrm{CeO}_{2}$-modified SNGC electrodes, with different concentrations of $\mathrm{CeO}_{2}$ nanoparticles $(0.25,0.5,0.75,1.0,2.5,5.0$, 7.5 and $10.0 \mathrm{mg} \cdot \mathrm{mL}^{-1}$ ), and six different AuSNPs $/ \mathrm{CeO}_{2}$-modified SNGC electrodes, with different w/w proportions of AuSNPs: $\mathrm{CeO}_{2}$ nanocomposite $(2.5 \%, 3.25 \%, 5 \%, 12.5 \%, 17.25 \%$ and $25 \%)$. The 
modified electrodes were built by depositing $3 \mu \mathrm{L}$ of the corresponding suspension on the surface of previously pre-treated bare SNGC electrodes.

\subsubsection{Cyclic Voltammetry Studies}

CV studies allow the evaluation of the electrochemical behavior of the devices (bare, $\mathrm{CeO}_{2}$-modified and AuSNPs/ $\mathrm{CeO}_{2}$-modified SNGC electrodes) both in the presence and absence of $1.00 \mathrm{mM} \mathrm{K}{ }_{4} \mathrm{Fe}(\mathrm{CN})_{6}$ solution. In presence of the mediator, the electrodes exhibited a pair of well-defined reversible redox peaks at $\sim 281 \mathrm{mV}$ and $\sim 193 \mathrm{mV}$, which are attributed to the oxidation and reduction processes of iron in the mediator. The separation of the peak potential values: $\Delta E_{p}=E_{a}-E_{c}$, is $88 \mathrm{mV}$. As it can be seen, this value is greater than $59 / \mathrm{n}(\mathrm{mV})$ as it should be for a totally reversible system. There was no redox peak in the absence of $\mathrm{K}_{4} \mathrm{Fe}(\mathrm{CN})_{6}$ (data not shown). It should be observed that the anodic and cathodic peak potentials did not shift when scan rates were increased, which can be also attributed to the reversible nature of the process. Stability of the electrodes has also proven to be rather good: after 20 successive measurements of $\mathrm{K}_{4} \mathrm{Fe}(\mathrm{CN})_{6}$ the results obtained for the peak current were almost the same, giving a relative standard deviation value less than $5 \%$.

Regarding the electrochemical mechanism that takes place on the surface of the electrodes, when studying the relationship of anodic and cathodic peak currents as a function of the square root of the scan rate $\left(v^{1 / 2}\right)$ (plots not shown), both parameters are proportional at the scan rates values studied $\left(10-100 \mathrm{mV} \cdot \mathrm{s}^{-1}\right)$ with correlation coefficients greater than 0.99 for all the electrodes tested: e.g., $i_{\mathrm{pa}}(\mu \mathrm{A})=0.326+0.131 \cdot v^{1 / 2}\left(\mathrm{mV} \cdot \mathrm{s}^{-1}\right), r=0.9982 ;$ and $i_{\mathrm{pc}}(\mu \mathrm{A})=-0.262-0.138 \cdot v^{1 / 2}\left(\mathrm{mV} \cdot \mathrm{s}^{-1}\right)$, $r=0.9982$ for the $\mathrm{CeO}_{2}\left(10 \mathrm{mg} \cdot \mathrm{ml}^{-1}\right)$-modified SNGC electrode, and $i_{\mathrm{pa}}(\mu \mathrm{A})=0.027+0.184 \cdot v^{1 / 2}\left(\mathrm{mV} \cdot \mathrm{s}^{-1}\right)$, $r=0.99997$; and $i_{\mathrm{pc}}(\mu \mathrm{A})=-0.035-0.186 \cdot v^{1 / 2}\left(\mathrm{mV} \cdot \mathrm{s}^{-1}\right), r=0.9998$, for the AuSNPs $/ \mathrm{CeO}_{2}(17.25 \% \mathrm{w} / \mathrm{w})-$ modified SNGC electrode, which indicates diffusion-controlled kinetics towards the electrode surface [34-37]. More evidence for the non-adsorptive behavior of $\mathrm{K}_{4} \mathrm{Fe}(\mathrm{CN})_{6}$ was demonstrated when the sensor was subjected to cyclic voltammetry scans in $0.2 \mathrm{M}$ PBS (pH 6.90). After being used in $\mathrm{K}_{4} \mathrm{Fe}(\mathrm{CN})_{6}$, no peak signal was obtained at all.

Figure 4 shows, as examples, the cyclic voltammograms corresponding to several electrodes: bare, $\mathrm{CeO}_{2}\left(0.75 \mathrm{mg} \cdot \mathrm{L}^{-1}\right)-, \mathrm{CeO}_{2}\left(10 \mathrm{mg} \cdot \mathrm{mL}^{-1}\right)-, \mathrm{AuSNPs} / \mathrm{CeO}_{2}(2.5 \% \mathrm{w} / \mathrm{w})-$ and $\mathrm{AuSNPs} / \mathrm{CeO}_{2}(25 \% \mathrm{w} / \mathrm{w})-$ modified SNGC electrodes both in presence and absence of $1.00 \mathrm{mM} \mathrm{K} 4 \mathrm{Fe}(\mathrm{CN})_{6}$ solution at $100 \mathrm{mV} \cdot \mathrm{s}^{-1}$. As it can be seen, the peak intensity values for both anodic and cathodic peaks are higher for the SNGC electrode modified with $\mathrm{CeO}_{2}$ nanoparticles or AuSNPs/CeO $/ \mathrm{C}_{2}$ nanocomposite than for the bare SNGC electrode. This is due to the more electroactive surface of the $\mathrm{CeO}_{2}$ - and the AuSNPs/CeO SNGC electrodes compared to the unmodified one. The presence of $\mathrm{CeO}_{2}$ nanoparticles and $\mathrm{AuSNPs} / \mathrm{CeO}_{2}$ nanocomposite on the electrodes surface increases the superficial area, and thus the electrochemical response versus the mediator $\left[\mathrm{K}_{4} \mathrm{Fe}(\mathrm{CN})_{6}\right]$. Furthermore, the peak intensity for the $\mathrm{CeO}_{2}\left(10 \mathrm{mg} \cdot \mathrm{mL}^{-1}\right)$ modified SNGC electrode was higher than that for the same type of electrode but with less $\mathrm{CeO}_{2}$ nanoparticles concentration, as shown in the figure. This is obviously due to an increase in the concentration of $\mathrm{CeO}_{2}$ nanoparticles deposited on the electrode surface which leads in turn to an increase in the number of $\mathrm{CeO}_{2}$ nanoparticles at the electrode surface, increasing the number of electroactive sites, and hence the peak intensity as well. 
Figure 4. CV voltammograms corresponding to different configurations of the SNGC electrodes tested for $1.00 \mathrm{M}$ of $\mathrm{K}_{4} \mathrm{Fe}(\mathrm{CN})_{6}$ recorded at $100 \mathrm{mV} \cdot \mathrm{s}^{-1}$ of scan rate.

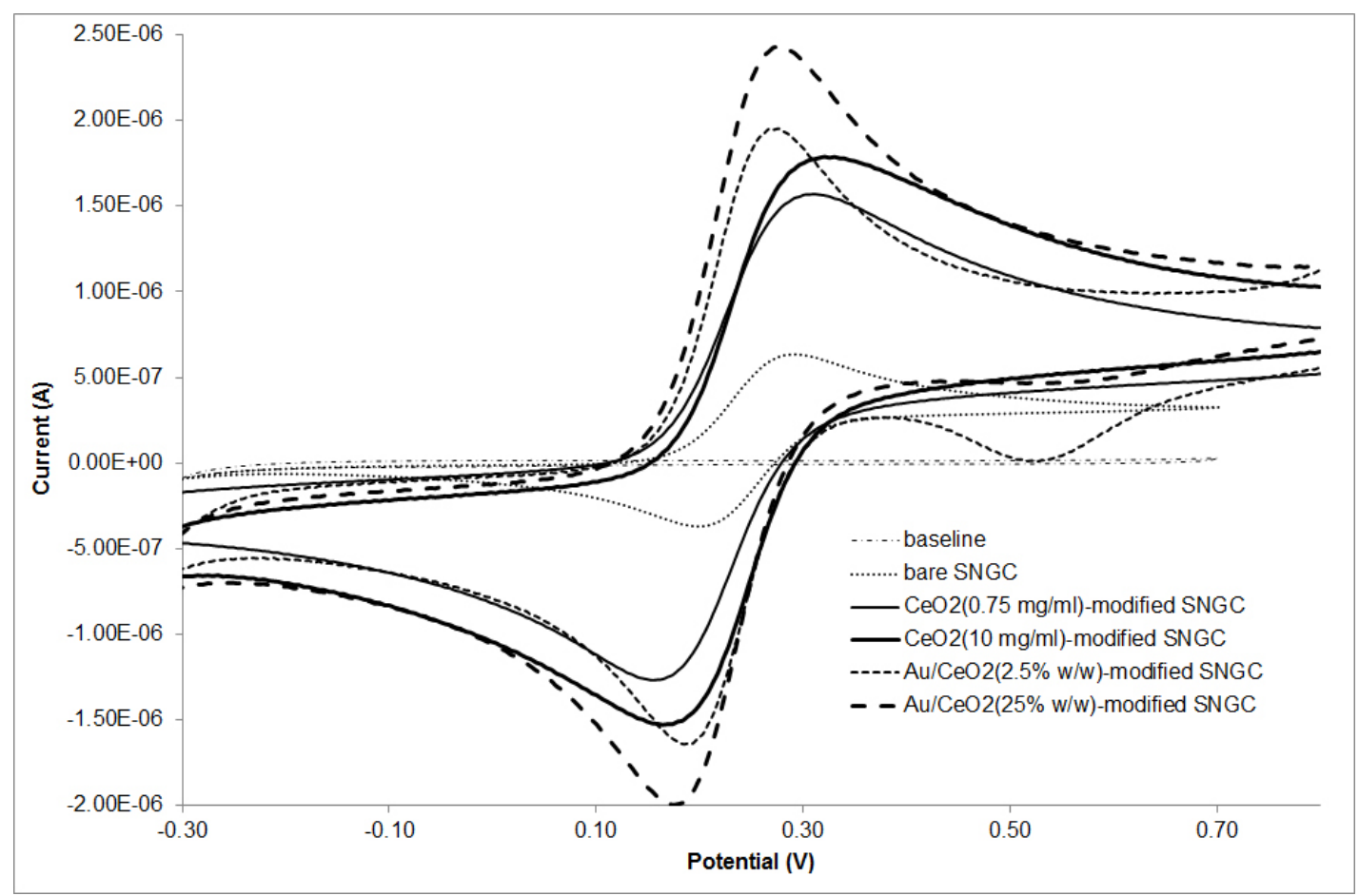

Besides, the peak intensity for AuSNPs $/ \mathrm{CeO}_{2}(25 \% \mathrm{w} / \mathrm{w})$-modified SNGC electrode was the highest, as Figure 4 shows. This fact can be explained in terms of the amount of $\mathrm{CeO}_{2}$ nanoparticles deposited on the electrodes' surface. Since the AuSNPs/CeO $2(25 \% \mathrm{w} / \mathrm{w})$-modified SNGC electrode presented the lowest amount of $\mathrm{CeO}_{2}$ nanoparticles of all the electrochemical devices built, and $\mathrm{CeO}_{2}$ nanoparticles possess greater isolating character than AuSNPs, the number of electroactive sites of AuSNPs increases at the electrode surface, and hence the peak intensity and the electrochemical response versus the mediator $\left[\mathrm{K}_{4} \mathrm{Fe}(\mathrm{CN})_{6}\right]$ as well. The same conclusions could be reached by taking into consideration the amount of gold on the devices' surface: the higher the AuSNPs: $\mathrm{CeO}_{2}$ proportion, the higher the current intensity. This result might suggest that electrodes modified with $\mathrm{AuSNPs} / \mathrm{CeO}_{2}$ nanocomposites perform better than electrodes modified only with $\mathrm{CeO}_{2}$ nanoparticles, due to its isolating properties. Moreover, SNGC electrodes modified with the AuSNPs $/ \mathrm{CeO}_{2}$ nanocomposite allow a shift in the mediator anodic peak towards less positive potentials: from $\sim 0.310 \mathrm{~V}$ (corresponding to the maximum of the peak for $\mathrm{CeO}_{2}$-modified electrodes) to $\sim 0.266 \mathrm{~V}$ (electrodes with the nanocomposite). However, antifouling properties of metal oxides should also be taken into account when considering the electrochemical performance of the devices.

Figure 5 depicts, as an example, the $\mathrm{CV}$ responses of AA at $\mathrm{AuSNPs} / \mathrm{CeO}_{2}(2.5 \% \mathrm{w} / \mathrm{w})$-modified SNGC electrode (solid lines) under various scan rates, as well as the bare SNGC response (dashed line) versus this mediator at $50 \mathrm{mV} \mathrm{s}^{-1}$. The plot of the redox peak current as function of the square root of scan rates is shown in the inset. 
Figure 5. $\mathrm{CV}$ voltammograms of $1.0 \mathrm{mM} \mathrm{AA}$, in $0.10 \mathrm{M}$ PBS (pH 6.9) at $\mathrm{AuSNPs} / \mathrm{CeO}_{2}$ $(2.5 \% \mathrm{w} / \mathrm{w})$-modified SNGC electrode (solid lines) at different scan rates: (a) 5; (b) 10; (c) 25; (d) $50 ;$ (e) 75; (f) 100; (g) 150; (h) $200 \mathrm{mV} \cdot \mathrm{s}^{-1}$ ), and at bare SNGC electrode (dashed line) at $50 \mathrm{mV} \cdot \mathrm{s}^{-1}$. The inset displays the plot of peak current against square root of scan rate.

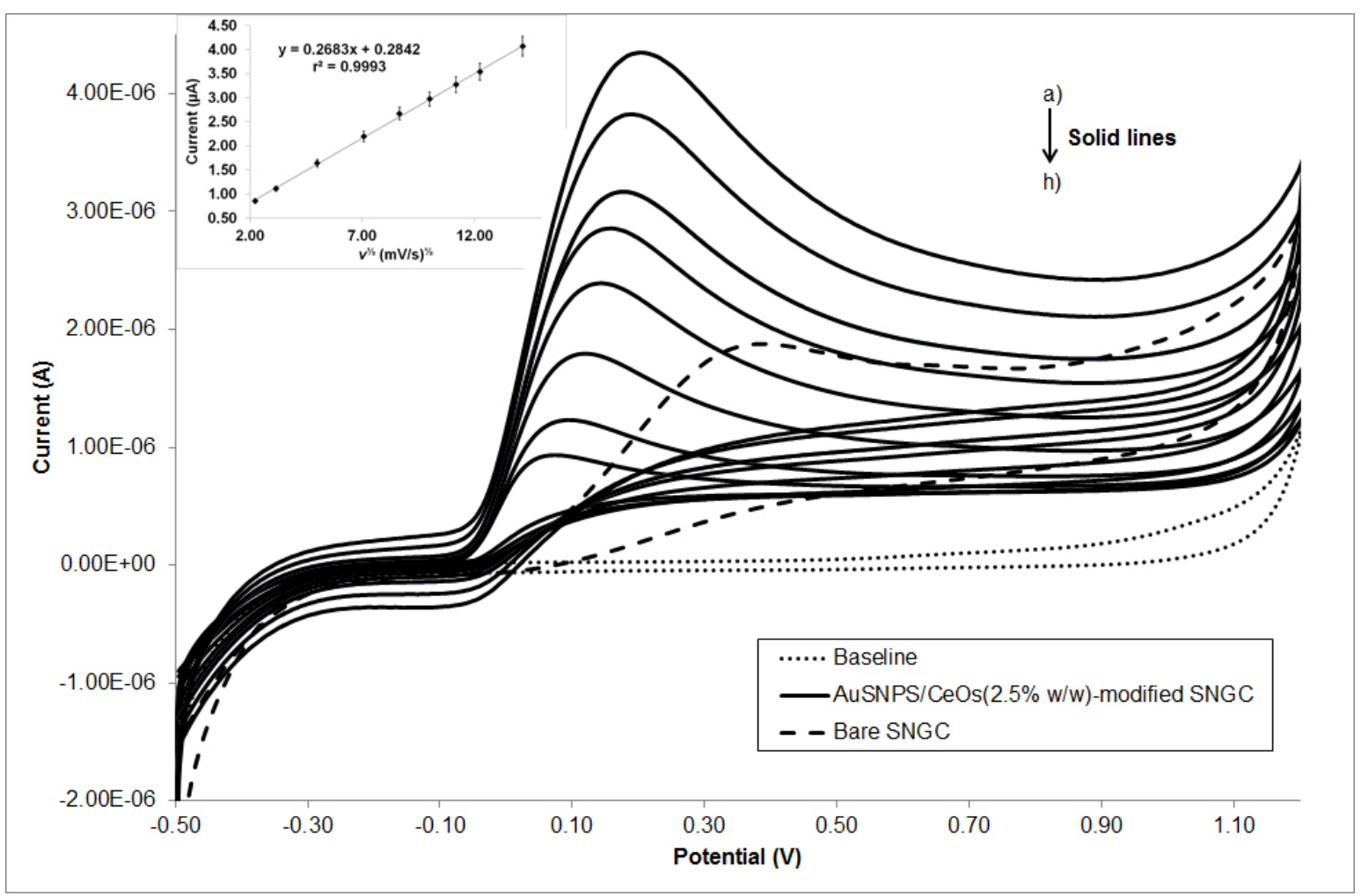

As it can be seen, good linear relationship is observed, indicating that this compound is electroactive under diffusion-controlled process at the AuSNPs $/ \mathrm{CeO}_{2}(2.5 \% \mathrm{w} / \mathrm{w})$-modified SNGC electrode. This figure also shows that $\mathrm{AA}$ is irreversibly electro-oxidized at the sensing device.

In order to get the information on the rate-determining step, Tafel slope, $b$, was determined using the following equation valid for a totally irreversible diffusion-controlled process [38]:

$$
E_{p}=\left(\frac{b}{2}\right) \log v+\text { constant }
$$

Therefore, on the basis of Equation (2), the slope of $E_{\mathrm{p}}$ versus $\log v$ plot is:

$$
\frac{d E_{p}}{d \log v}=\frac{b}{2}
$$

where $b$ is the Tafel slope and $v$ is the scan rate; the Tafel slope can also be expressed as:

$$
b=2.3 R T\left(\alpha_{a} n_{\alpha} F\right)^{-1}
$$

On the basis of these equations, the slope of the plots of $E_{\mathrm{p}}$ versus $\log v$ is $b / 2$ which was found equal to 0.0628 in this work as the following linear equation states: $E_{\mathrm{p}}(\mathrm{V})=0.0628 \cdot \log v(\mathrm{mV} / \mathrm{s})+0.0275$, with a $r^{2}$ value equal to 0.9992 ; so, $b=2 \times 0.0628 \mathrm{~V}=0.126 \mathrm{~V}$. It is known that ascorbic acid oxidation 
kinetics on many materials [38-41] occurs with single electron transfer process. Assuming this, these slope values indicate a transfer coefficient $(\alpha)$ equal to 0.4699 , which in most systems turns out to lie between $0.3-0.7$ [35].

The number of electrons involved in the rate determining step, can be obtained using another method. Tafel plots (Figure 6) were drawn using the data from the rising part of the current-voltage curve at a scan rate of $50 \mathrm{mV} \cdot \mathrm{s}^{-1}$ for three different concentration of AA: 1, 2 and $3 \mathrm{mM}$.

Figure 6. Tafel plots derived from current-potential curves obtained on the AuSNPs $/ \mathrm{CeO}_{2}(2.5 \% \mathrm{w} / \mathrm{w})$-modified SNGC electrode in the presence of different AA concentrations: (a) 1, (b) 2 and (c) $3 \mathrm{mM}$ at a scan rate of $50 \mathrm{mV} \cdot \mathrm{s}^{-1}$ in PBS $0.2 \mathrm{M}$.

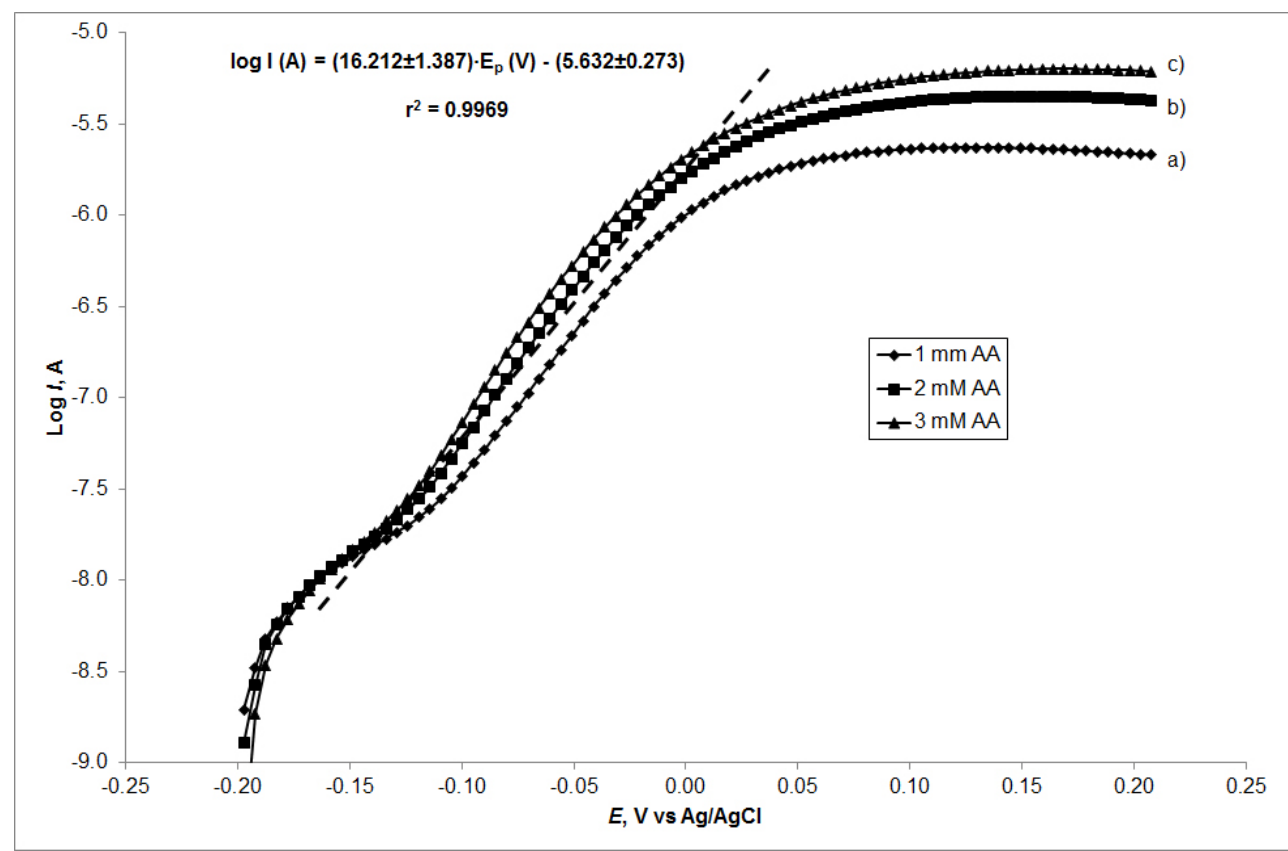

A mean slope of $0.0617 \mathrm{~V} \cdot \mathrm{decade}^{-1}$ or $16.21\left(\mathrm{~V} \cdot \mathrm{decade}^{-1}\right)^{-1}$ was obtained presenting a one-electron process which was rate limiting assuming a transfer coefficient of $\alpha=0.4785$. The results obtained from the two different methods are in good agreement.

Some questions concerning the capacity of the electrodes should be stated. This parameter gives an idea about the amount of charge that is stored in the electrode at a given potential value. It corresponds to the non-faradaic current, i.e., the amount of charge that is not used to oxidize or reduce an electroactive species. To evaluate the behavior of our electrodes, cyclic voltammograms were carried out in phosphate buffer solution $0.2 \mathrm{M}$ at $\mathrm{pH}$ 6.9. In our study we have calculated the corresponding values of the experimental observed capacity and the double-layer capacity (Table 1). The observed capacity is defined as $C_{\mathrm{obs}}=i / v$, where $i$ is the average anodic and cathodic current density and $v$ is the scan rate $\left(100 \mathrm{mV} \cdot \mathrm{s}^{-1}\right)$, and the double-layer capacity $\left(C_{\mathrm{dl}}\right)$ consists of the slope of the regression line obtained when representing the average (absolute) values of the anodic and cathodic current densities at different scan rates (from 10 to $100 \mathrm{mV} \cdot \mathrm{s}^{-1}$ ) versus the scan rate values. As an example, we show the regression equation: $J_{\text {average }}\left(\mu \mathrm{A} \cdot \mathrm{cm}^{-2}\right)=149.656 \cdot v\left(\mathrm{mV} \cdot \mathrm{s}^{-1}\right)+0.333, r=0.9988$, corresponding to the $\mathrm{CeO}_{2}\left(0.5 \mathrm{mg} \cdot \mathrm{ml}^{-1}\right)$-modified SNGC electrode. 
Table 1. Experimental values of the observed capacity $\left(C_{\text {obs }}\right)$ at $100 \mathrm{mV} \cdot \mathrm{s}^{-1}$ and the doublelayer capacity $\left(C_{\mathrm{dl}}\right)$ for the different configurations of the Sonogel-Carbon electrodes.

\begin{tabular}{|c|c|c|}
\hline Electrode & $\mathrm{C}_{\mathrm{obs}}\left(\mu \mathrm{F} / \mathrm{cm}^{2}\right) \pm \mathrm{SD} *$ & $C_{d l}\left(\mu F / \mathrm{cm}^{2}\right) \pm S D$ \\
\hline Bare SNGC & $28 \pm 1.76$ & $24 \pm 0.78$ \\
\hline $\mathrm{CeO}_{2}\left(0.25 \mathrm{mg} \cdot \mathrm{mL}^{-1}\right)$-modified SNGC & $46.82 \pm 2.75$ & $46.08 \pm 4.49$ \\
\hline $\mathrm{CeO}_{2}\left(0.75 \mathrm{mg} \cdot \mathrm{mL}^{-1}\right)$-modified SNGC & $73.38 \pm 8.87$ & $72.44 \pm 5.63$ \\
\hline $\mathrm{CeO}_{2}\left(1.0 \mathrm{mg} \cdot \mathrm{mL}^{-1}\right)$-modified SNGC & $105.83 \pm 1.26$ & $108.8 \pm 8.56$ \\
\hline $\mathrm{CeO}_{2}\left(2.5 \mathrm{mg} \cdot \mathrm{mL}^{-1}\right)$-modified SNGC & $237.07 \pm 6.97$ & $228.14 \pm 10.19$ \\
\hline $\mathrm{CeO}_{2}\left(5.0 \mathrm{mg} \cdot \mathrm{mL}^{-1}\right)$-modified SNGC & $243.24 \pm 0.09$ & $238.80 \pm 3.96$ \\
\hline AuSNPs/CeO $2(25 \%$ w/w)-modified SNGC & $99.86 \pm 10.17$ & $98.02 \pm 10.68$ \\
\hline $\mathrm{AuSNPs} / \mathrm{CeO}_{2}(12.5 \% \mathrm{w} / \mathrm{w})$-modified SNGC & $97.96 \pm 1.78$ & $96.47 \pm 3.56$ \\
\hline $\mathrm{AuSNPs} / \mathrm{CeO}_{2}(5 \% \mathrm{w} / \mathrm{w})$-modified SNGC & $44.97 \pm 3.47$ & $43.96 \pm 0.65$ \\
\hline AuSNPs $/ \mathrm{CeO}_{2}(2.5 \% \mathrm{w} / \mathrm{w})-\mathrm{CeO}_{2}$-modified SNGC & $40.94 \pm 10.35$ & $41.93 \pm 7.39$ \\
\hline
\end{tabular}

* SD: Standard Deviation.

As observed in Table 1, as expected the lower value for the capacities corresponds to the unmodified SNGC electrode, taken as reference value, since this parameter increases its values because of the presence of chemical species (modifiers) on the surface of the electrodes. The $C_{\mathrm{obs}}$ value for the unmodified electrode shows perfect correspondence with previously published results $[32,42]$. On one hand and in general terms, when depositing $\mathrm{CeO}_{2}$ nanoparticles on the surface of the SNGC electrodes the capacity values increase: the higher the amount of nanoparticles, the greater the capacity values. This is probably due to the resistive character of the $\mathrm{CeO}_{2}$ film. On the other hand, concerning the AuSNPs $/ \mathrm{CeO}_{2}$-modified SNGC electrodes, the capacity values decreases with the $\mathrm{AuSNPs} / \mathrm{CeO}_{2}$ percentage (consider that the lower the percentage value, the higher the $\mathrm{CeO}_{2}$ concentration), despite of the presence of AuSNPs. This might be attributed to the fact that gold nanoparticles are not directly in contact with the electrode surface and that current mainly flows through the $\mathrm{CeO}_{2}$ nanoparticles (in a very high percentage with respect to gold) to the transducer. According to this, it seems that when modifying SNGC electrodes with the AuSNPs/CeO 2 nanocomposite, the capacity values are lower than when modifying only with $\mathrm{CeO}_{2}$. This means that a AuSNPs/ $\mathrm{CeO}_{2}$-modified $\mathrm{SNGC}$ electrode stores much less amount of charge, and hence much more charge is available to oxidize and/or reduce the analytes. In general, the lower the capacity values, the better the electrochemical performance of the electrodes.

To finish with the $\mathrm{CV}$ studies, the effect of ascorbic acid concentration on the cyclic voltammetric response of $\mathrm{CeO}_{2}$ - and $\mathrm{AuSNPs} / \mathrm{CeO}_{2}$-modified SNGC electrodes was investigated. Figure 7 shows, as an example, the cyclic voltammograms of the AuSNPs $/ \mathrm{CeO}_{2}(2.5 \% \mathrm{w} / \mathrm{w})$-modified SNGC electrode at the presence of various concentrations of ascorbic acid. With increasing AA concentration in the solution, the anodic peak current is increased. This catalytic peak current has a linear relationship with the concentration of $\mathrm{AA}$ in the range of $0.01-5 \mathrm{mM}$ with a correlation coefficient of 0.9995 (inset of Figure 7). From these results, we can conclude that the electro-oxidation of AA on these electrodes can be used for the quantitative determination of this analyte in samples, being the simplicity of preparation of the electrodes described here other advantage to be taken into account. 
Figure 7. The cyclic voltammograms of AuSNPs $/ \mathrm{CeO}_{2}(2.5 \% \mathrm{w} / \mathrm{w})$-modified $\mathrm{SNGC}$ electrode in $0.2 \mathrm{M}$ PBS with different concentrations of ascorbic acid: (a) 0.01 ; (b) 0.1 ; (c) 0.5 ; (d) 1.0 ; (e) 2.0; (f) 3.0 ; (g) 4,0; (h) 5,0 mM. The inset displays the AA oxidation peak current on this electrode versus concentration of the analyte.

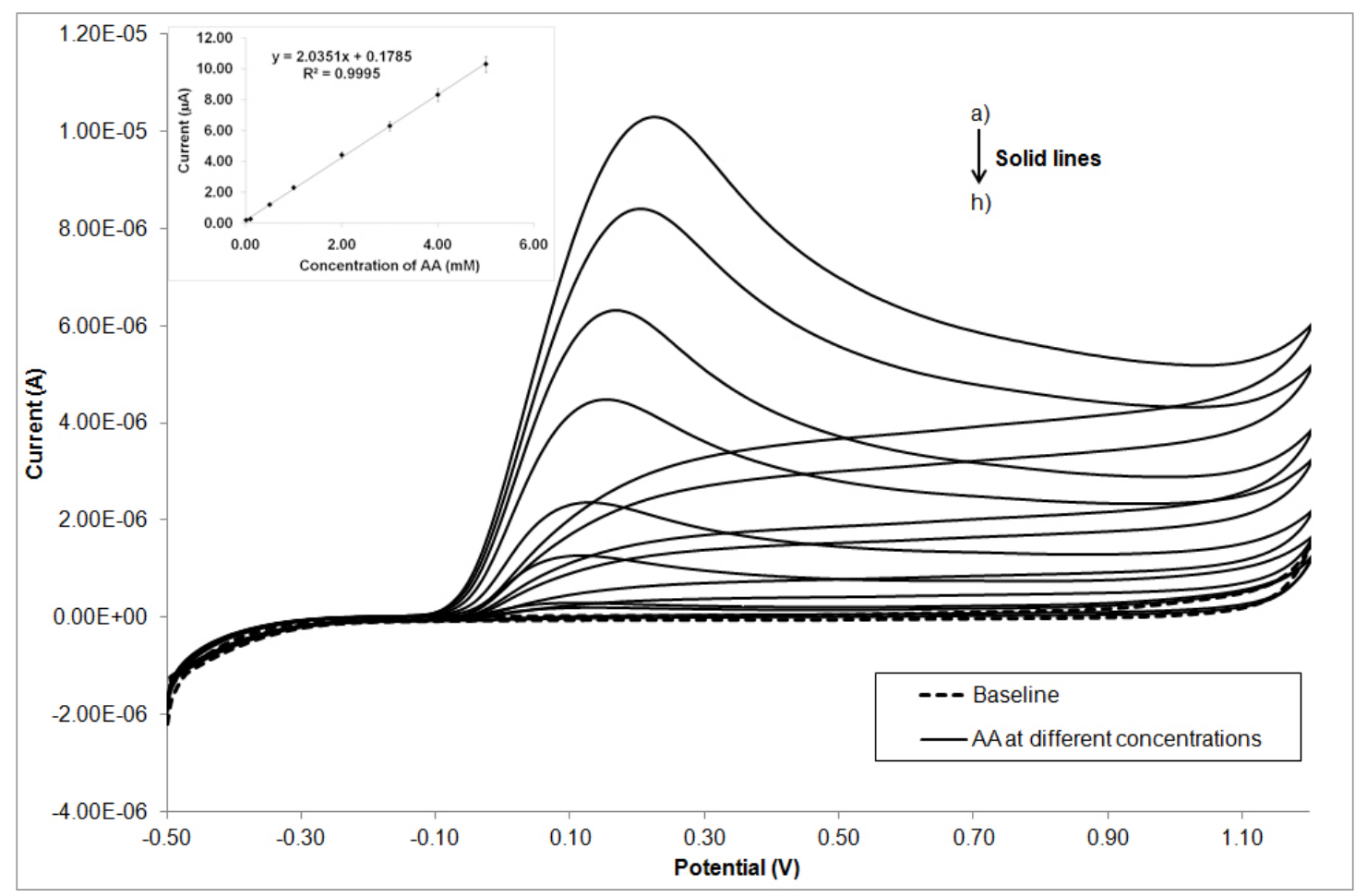

\subsubsection{Differential Pulse Voltammetry Studies}

Pulse voltammetry techniques have been established to be very sensitive in the detection of micromolar amounts of chemical species, particularly AA [9,34,43]. Thus, differential pulse voltammetry (DPV) has been used to evaluate and demonstrate the good electrochemical performance of our devices when determining AA selected as benchmark analyte.

In the literature, the effect of the DPV parameters on the response of the electrodes has been studied by means of three factors and three levels Box-Behnken experimental design [44]. These investigations allowed us to individuate the scan parameters leading to optimal sensitivity of the devices. According to our experience and previous studies [9], the optimal combination of DPV parameters chosen for these studies was as follows: interval time $(\mathrm{IT})=0.4 \mathrm{~s}$, step potential $(\mathrm{SP})=16 \mathrm{mV}$ and modulation amplitude $(\mathrm{MA})=100 \mathrm{mV}$. Using this combination of parameters several calibration curves for AA at the scan rate of $50 \mathrm{mV} \cdot \mathrm{s}^{-1}$ were obtained by using the SNGC electrodes at different configurations. The potential range at which the sensor responses were studied was from $-0.5 \mathrm{~V}$ to $0.7 \mathrm{~V}$ in a $0.2 \mathrm{M}$ PBS (pH 6.9) buffer solution.

Together with the determination coefficient that give us an idea about the goodness of the regression model, special attention was also paid to the slope of the regression lines, which represents the sensitivity (measured in $\mathrm{A} \cdot \mathrm{M}^{-1}$ ) of the sensor for this analyte. The calibration curves were obtained for an AA concentration range from $1.5 \times 10^{-6} \mathrm{M}\left(0.25 \mathrm{mg} \cdot \mathrm{L}^{-1}\right)$ to $4.0 \times 10^{-3} \mathrm{M}\left(700 \mathrm{mg} \cdot \mathrm{L}^{-1}\right)$. For each calibration curve, 18 points at different AA concentrations within this range (three orders of 
magnitude) were measured, with three replicates. One example of the calibration curve obtained for AA when using AuSNPs $/ \mathrm{CeO}_{2}(5 \% \mathrm{w} / \mathrm{w})$-modified SNGC electrode is: $I(\mathrm{~A})=1.209 \times 10^{-3} \cdot[\mathrm{AA}]$ $\left(\mathrm{A} \cdot \mathrm{M}^{-1}\right)-4.265 \times 10^{-9}, r^{2}=0.9995$. The relationship between concentration of AA and current peak height was linear in the concentration range studied. In Figure 8, an example of the DPV voltammograms corresponding to the calibration curve (inset) for electrocatalysis of ascorbic acid is shown.

Figure 8. DPV voltammograms corresponding to one calibration curve (inset) for ascorbic acid using a AuSNPs/CeO 2 (5\% w/w)-modified SNGC electrode.

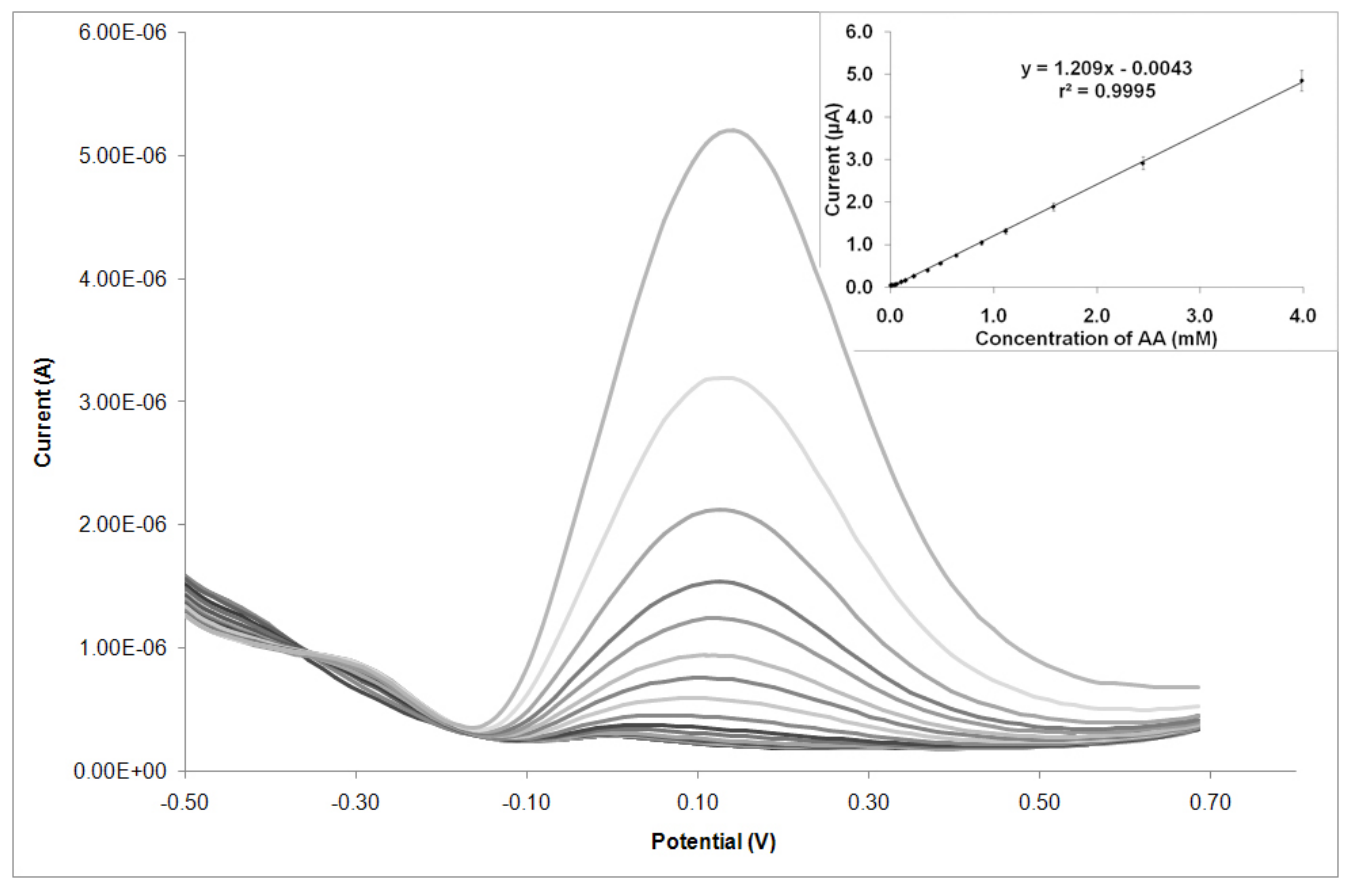

Table 2. Results of the calibration curves obtained for AA when using the different types of Sonogel-Carbon electrodes employed.

\begin{tabular}{|c|c|c|}
\hline Electrode & Slope $\left(\times 10^{-3} \mathrm{~A} / \mathrm{M}\right)$ & $\mathbf{r}^{2}$ \\
\hline Bare SNGC & 2.31 & 0.99991 \\
\hline $\mathrm{CeO}_{2}\left(0.25 \mathrm{mg} \cdot \mathrm{mL}^{-1}\right)$-modified SNGC & 1.31 & 0.99845 \\
\hline $\mathrm{CeO}_{2}\left(0.5 \mathrm{mg} \cdot \mathrm{mL}^{-1}\right)$-modified SNGC & 0.86 & 0.99763 \\
\hline $\mathrm{CeO}_{2}\left(0.75 \mathrm{mg} \cdot \mathrm{mL}^{-1}\right)$-modified SNGC & 1.26 & 0.99996 \\
\hline $\mathrm{CeO}_{2}\left(1.0 \mathrm{mg} \cdot \mathrm{mL}^{-1}\right)$-modified SNGC & 0.95 & 0.99910 \\
\hline $\mathrm{CeO}_{2}\left(2.5 \mathrm{mg} \cdot \mathrm{mL}^{-1}\right)$-modified SNGC & 1.03 & 0.99966 \\
\hline $\mathrm{CeO}_{2}\left(5.0 \mathrm{mg} \cdot \mathrm{mL}^{-1}\right)$-modified SNGC & 1.29 & 0.99990 \\
\hline $\mathrm{CeO}_{2}\left(7.5 \mathrm{mg} \cdot \mathrm{mL}^{-1}\right)$-modified SNGC & 1.02 & 0.99994 \\
\hline $\mathrm{CeO}_{2}\left(10.0 \mathrm{mg} \cdot \mathrm{mL}^{-1}\right)$-modified SNGC & 1.10 & 0.99832 \\
\hline $\mathrm{AuSNPs} / \mathrm{CeO}_{2}(25 \% \mathrm{w} / \mathrm{w})$-modified SNGC & 1.42 & 0.99995 \\
\hline $\mathrm{AuSNPs} / \mathrm{CeO}_{2}(17.25 \% \mathrm{w} / \mathrm{w})$-modified SNGC & 1.38 & 0.99969 \\
\hline $\mathrm{AuSNPs} / \mathrm{CeO}_{2}(12.5 \% \mathrm{w} / \mathrm{w})$-modified SNGC & 0.97 & 0.99900 \\
\hline AuSNPs/CeO 2 (5\% w/w)-modified SNGC & 1.19 & 0.99974 \\
\hline $\mathrm{AuSNPs} / \mathrm{CeO}_{2}(3.25 \% \mathrm{w} / \mathrm{w})-\mathrm{CeO}_{2}$-modified SNGC & 1.31 & 0.99965 \\
\hline $\mathrm{AuSNPs} / \mathrm{CeO}_{2}(2.5 \% \mathrm{w} / \mathrm{w})-\mathrm{CeO}_{2}$-modified SNGC & 1.02 & 0.99940 \\
\hline
\end{tabular}


Table 2 shows the calibration curves obtained for the different types of SNGC electrodes used throughout this research work, in terms of slope and determination coefficient values. From the table, it can be seen that the electrochemical performance of electrodes modified with $\mathrm{CeO}_{2}$ and $\mathrm{AuSNPs} / \mathrm{CeO}_{2}$ nanoparticles are similar. On one hand, it seems that in general the higher the $\mathrm{CeO}_{2}$ concentration on the electrode surface, the lower the slope of the calibration curves and hence the sensitivity. This can be explained in terms of the resistive character of the $\mathrm{CeO}_{2}$ film: the current must flow through this film to the electrode surface. On the other hand, regarding the AuSNPs $/ \mathrm{CeO}_{2}$-modified-SNGC electrodes, similar results could be obtained: electrodes modified with higher proportion of AuSNPs seem to offer better sensitivity (consider that the higher the percentage, the lower the $\mathrm{CeO}_{2}$ concentration). However, it seems that the decoration with AuSNPs does not show significant advantages with respect to sensitivity, perhaps because of the high thickness of the $\mathrm{CeO}_{2}$ film, which seems to be a determinant factor concerning sensitivity of the electrodic devices. The modified device that shows the higher sensitivity corresponds to AuSNPs $/ \mathrm{CeO}_{2}(25 \% \mathrm{w} / \mathrm{w})$-modified SNGC electrode, which is also one of the electrochemical devices with the lowest capacity values when measuring $\mathrm{K}_{4} \mathrm{Fe}(\mathrm{CN})_{6}$. For application purposes, it would be advisable to achieve a compromise between sensitivity and capacity.

When comparing bare and modified SNGC electrodes; the sensitivity is higher with no modifications of the electrode surface. This is probably related to the place where electrochemical reactions (redox reactions) of the analyte takes place; from the results obtained; it seems that electrooxidation and/or electroreduction occurs at the surface of the bare SNGC electrode; but in case of modified-SNGC devices these reactions occur at the surface of $\mathrm{CeO}_{2}$ and $\mathrm{AuSNPs} / \mathrm{CeO}_{2}$ nanoparticles. The presence of the $\mathrm{CeO}_{2}$ nanoparticles film at the surface of the electrodes increases their electrochemical resistance. Moreover; due to the different nature of the electrocatalytic processes taking place on smooth electrode surface and on nanoparticles surface; it might not be possible to compare directly the slopes of bare and modified SNGC electrodes (or at least doing it with special care).

Reproducibility and repeatability studies were performed as well. In the case of the reproducibility studies, several calibration curves for AA were obtained by using three different SNGC electrodes for each one of the configurations tested. The results expressed in terms of the average slope and the respective coefficients of variation are shown in Table 3.

As it can be seen, the results are coherent with those reported previously in Table 1 . The trend and the average slope values, in general, are similar for all the configurations, excepting for the bare SNGC electrode, due to the same reasons discussed previously. Regarding the coefficient of variation for the slope, excepting for the less concentrated $\mathrm{CeO}_{2}$-modified devices and the one deposited with AuSNPs $/ \mathrm{CeO}_{2}(25 \% \mathrm{w} / \mathrm{w})$, the values are rather good in general, being better for $\mathrm{AuSNPs} / \mathrm{CeO}_{2}-$ than for $\mathrm{CeO}_{2}$-modified SNGC electrodes and remarkable for $\mathrm{CeO}_{2}\left(2.5 \mathrm{mg} \cdot \mathrm{mL}^{-1}\right)$-, $\mathrm{AuSNPs} / \mathrm{CeO}_{2}$ $(5 \% \mathrm{w} / \mathrm{w})-$ and AuSNPs $/ \mathrm{CeO}_{2}(17.25 \% \mathrm{w} / \mathrm{w})$-modified SNGC. This means that: (i) the three quoted electrodes perform better in terms of reproducibility, despite the high number of measurement that are necessary to be done with only one electrode to obtain a single calibration curve; (ii) the process of fabrication of the electrodes is also very reproducible, what is very difficult for modified composite electrodes (the Sonogel-Carbon material fabrication process and the deposition of $\mathrm{CeO}_{2}$ and AuSNPs $/ \mathrm{CeO}_{2}$ nanoparticles); iii) for application purposes, a compromise among reproducibility, sensitivity and capacity values should be achieved. 
Table 3. Results obtained for the reproducibility and repeatability studies by using three different SNGC electrodes and the same SNGC electrode (with at least three different calibration curves for each electrode), respectively, and the best detection and quantification limits for each one of the configurations tested.

\begin{tabular}{|c|c|c|c|c|c|c|}
\hline \multirow[b]{2}{*}{ Electrode } & \multicolumn{2}{|c|}{ Reproducibility Studies } & \multicolumn{2}{|c|}{ Repeatability Studies } & \multirow[b]{2}{*}{$\begin{array}{c}\mathrm{LD} \\
\left(\times 10^{-6}\right. \\
\mathrm{M})\end{array}$} & \multirow[b]{2}{*}{$\begin{array}{c}\text { LQ } \\
\left(\times 10^{-5}\right. \\
\mathrm{M})\end{array}$} \\
\hline & $\begin{array}{l}\text { Average slope } \\
\left(\times 10^{-3} \mathrm{~A} \cdot \mathrm{M}^{-1}\right)\end{array}$ & $\begin{array}{c}\text { CV of } \\
\text { slope }(\%)\end{array}$ & $\begin{array}{c}\text { Average } \\
\text { slope }\left(\times 10^{-3}\right. \\
\left.\mathrm{A} \cdot \mathrm{M}^{-1}\right)\end{array}$ & $\begin{array}{l}\text { CV of } \\
\text { slope } \\
(\%)\end{array}$ & & \\
\hline Bare SNGC & 2.173 & 12.09 & 1.886 & 0.11 & 11.30 & 3.78 \\
\hline $\mathrm{CeO}_{2}\left(0.25 \mathrm{mg} \cdot \mathrm{mL}^{-1}\right)$-modified SNGC & 1.015 & 9.77 & 1.072 & 0.67 & 0.55 & 1.83 \\
\hline $\mathrm{CeO}_{2}\left(0.5 \mathrm{mg} \cdot \mathrm{mL}^{-1}\right)$-modified SNGC & 0.743 & 13.27 & 0.834 & 3.10 & 1.19 & 3.96 \\
\hline $\mathrm{CeO}_{2}\left(0.75 \mathrm{mg} \cdot \mathrm{mL}^{-1}\right)$-modified SNGC & 1.054 & 21.71 & 1.236 & 1.96 & 0.16 & 0.52 \\
\hline $\mathrm{CeO}_{2}\left(1.0 \mathrm{mg} \cdot \mathrm{mL}^{-1}\right)$-modified SNGC & 0.807 & 16.23 & 0.918 & 3.37 & 1.59 & 5.32 \\
\hline $\mathrm{CeO}_{2}\left(2.5 \mathrm{mg} \cdot \mathrm{mL}^{-1}\right)$-modified SNGC & 0.991 & 2.71 & 0.995 & 3.19 & 2.51 & 8.36 \\
\hline $\mathrm{CeO}_{2}\left(5.0 \mathrm{mg} \cdot \mathrm{mL}^{-1}\right)$-modified SNGC & 0.968 & 7.06 & 1.051 & 4.78 & 4.14 & 13.79 \\
\hline $\mathrm{CeO}_{2}\left(7.5 \mathrm{mg} \cdot \mathrm{mL}^{-1}\right)$-modified SNGC & 0.935 & 7.67 & 0.943 & 7.17 & 3.88 & 12.94 \\
\hline $\mathrm{CeO}_{2}\left(10.0 \mathrm{mg} \cdot \mathrm{mL}^{-1}\right)$-modified SNGC & 1.043 & 5.78 & 1.085 & 1.86 & 1.59 & 5.29 \\
\hline AuSNPs $/ \mathrm{CeO}_{2}(25 \%$ w/w)-modified SNGC & 0.993 & 35.42 & 1.273 & 10.89 & 1.81 & 6.05 \\
\hline AuSNPs/CeO $2(17.25 \%$ w/w)-modified SNGC & 1.113 & 2.99 & 1.216 & 11.69 & 1.23 & 4.11 \\
\hline AuSNPs $/ \mathrm{CeO}_{2}(12.5 \% \mathrm{w} / \mathrm{w})$-modified SNGC & 0.868 & 6.59 & 0.891 & 8.26 & 3.06 & 10.20 \\
\hline $\mathrm{AuSNPs} / \mathrm{CeO}_{2}(5 \% \mathrm{w} / \mathrm{w})$-modified SNGC & 1.159 & 3.29 & 1.159 & 4.03 & 6.57 & 21.89 \\
\hline $\mathrm{AuSNPs} / \mathrm{CeO}_{2}(3.25 \% \mathrm{w} / \mathrm{w})-\mathrm{CeO}_{2}$-modified SNGC & 1.223 & 6.24 & 1.285 & 2.48 & 2.93 & 9.77 \\
\hline $\mathrm{AuSNPs} / \mathrm{CeO}_{2}(2.5 \% \mathrm{w} / \mathrm{w})-\mathrm{CeO}_{2}$-modified SNGC & 0.800 & 8.05 & 0.892 & 13.34 & 2.62 & 8.75 \\
\hline
\end{tabular}

With respect to the repeatability studies also reported in Table 3, a SNGC electrode for each configuration was tested and the average slope and the coefficient of variation for the slope for at least three calibration curves using the same electrode were also obtained. In general, modified SNGC electrodes showed similar and rather good repeatability results. Moreover, excepting for several $\mathrm{AuSNPs} / \mathrm{CeO}_{2}-$ modified SNGC electrodes, the repeatability values were remarkable good in all cases (under 7\%-8\%). It seems that for devices with higher coefficient of variation value some problem with the deposition took place or an unexpected degradation of the electrode surface (see Section 3.4.1) occurred due to the weight and thickness of the film as well as the intensive use of the amperometric sensor.

Some comments concerning the detection and quantification limits (LD and LQ, respectively) for the electrodes tested at different configurations are warranted. Table 3 shows the values obtained for both LD and LQ for each configuration of the SNGC electrodes. LD was calculated as three times the standard deviation of the blank and LQ as ten times this value as reported by Miller and Miller [45]. On one hand, in case of $\mathrm{CeO}_{2}$-modified SNGC electrodes, the lower the concentration of $\mathrm{CeO}_{2}$ nanoparticles, the better the LD and LQ values, being remarkable for the $\mathrm{CeO}_{2}\left(0.75 \mathrm{mg} \cdot \mathrm{ml}^{-1}\right)$ modified SNGC electrode; however, it should be taken into accoSunt that reproducibility of this electrode is not very good. Perhaps $\mathrm{CeO}_{2}\left(10.0 \mathrm{mg} \cdot \mathrm{mL}^{-1}\right)$-modified device could be considered instead. Nevertheless, these values are more or less similar in all cases and within the units or tenths of micromolar range. On the other hand, concerning, AuSNPs/ $/ \mathrm{CeO}_{2}$-modification, the lowest $\mathrm{LD}$ and LQ values were obtained for $\mathrm{AuSNPs} / \mathrm{CeO}_{2}(3.25 \% \mathrm{w} / \mathrm{w})$-modified SNGC electrode, although as it 
happened with the $\mathrm{CeO}_{2}$ modified devices, the results were similar in all cases. Finally, when comparing between bare and modified-SNGC electrodes, the best values are clearly obtained for modified ones. This means that both $\mathrm{CeO}_{2}$ and $\mathrm{AuSNPs} / \mathrm{CeO}_{2}$ nanoparticles, overall the first one for its resistive character and its higher concentration versus AuSNPs, play an important role in the determination of AA.

In comparison with some reported AA sensors [9,12,31,41,46-57] (see Table 4), modified with $\mathrm{CeO}_{2}$ nanoparticles, AuNPs, AuNPs $/ \mathrm{CeO}_{2}$ nanocomposite, or with other types of modifiers, the electrochemical device that we propose shows very important advantages with respect to others found in literature: (i) SNGC electrodes are modified with both types of nanomaterials (AuSNPs and $\mathrm{CeO}_{2}$ nanoparticles) simply by drop casting method, and the proposed methodology shows results that are in the same range, and in some cases, are better than most of those reported in literature by using more complex systems for electrode modification; (ii) some of the $\mathrm{CeO}_{2}$ - and $\mathrm{AuSNPs} / \mathrm{CeO}_{2}-$ modified SNGC electrodes are rather sensitive with a relatively high linear range simultaneously; besides, these modified electrodes are easy of fabrication, low cost and can be used for many times, showing high reproducibility and repeatability; (iii) the electro-oxidation signal corresponding to AA appears at less positive potentials values $(0.140 \mathrm{~V})$ than most of methodologies reported in literature. This research suggests that these modified electrodes could be very promising voltammetric sensors for the determination of AA. It has to be taken into consideration that there are only a few papers (see Table 4) reporting determination of AA with $\mathrm{CeO}_{2}$-modified electrodes and that up to the extent of our knowledge this is the first time that AA has been determined by means of a $\mathrm{AuNPs} / \mathrm{CeO}_{2}$ nanocomposite-modified electrode.

Moreover, when comparing our system with other electrochemical quantification methods for AA, it is noteworthy that DPV is the most extended method to determine AA. According to Table 4, amperometry leads to lower detection limits than typical voltammetric techniques as CV or DPV, and when using SWV results are rather good, being in a similar range than those obtained for DPV. However, when looking at DPV only, it seems that the improvement in the figure of merits depends strongly on the electrochemical device employed, and mainly in the modification of the electrode. Our devices, modified with $\mathrm{CeO}_{2}$ nanoparticles and $\mathrm{AuSNPs} / \mathrm{CeO}_{2}$ nanocomposite, as stated before, performs rather well, with lower detection limits and greater dynamic range than other more complex modified devices such as $\beta$-CD-nanoAu/Fc-ITO, AuNPs/silica/MWCNT/GCE or AuNPs/ $\beta$-CD/graphene/GCE. Besides, some other advantages, as those described above, can be noted as well.

\subsection{Real Sample Application}

Some tests of the electrochemical devices used throughout this work were done to determine ascorbic acid (vitamin C) in commercial apple juices for babies. The determination of AA in the real samples was carried out by the standard addition method in order to prevent any matrix effects. Moreover, the results obtained by the electroanalytical techniques were compared with those obtained by HPLC, taken as a reference method. It is noteworthy that this is the first time that electrochemical sensors based on the nanocomposite as the one reported in this work has been applied to the determination of AA in commercial apple juices for babies as real sample. 
Table 4. Comparison of different $\mathrm{CeO}_{2-}$, AuNPs- and AuNPs $/ \mathrm{CeO}_{2-}$ modified electrodes for AA determination.

\begin{tabular}{|c|c|c|c|c|c|}
\hline Electrode & Method & $\begin{array}{l}\text { LOD }^{1} \\
(\mu M)\end{array}$ & $\begin{array}{l}\text { Linear Range } \\
(\mu \mathrm{M})\end{array}$ & $\mathbf{E}(\mathbf{V})$ & Refs. \\
\hline BCD-nanoAu/Fc-ITO & $\mathrm{CV}$ & 4.1 & $53-3,000$ & 0.572 & {$[46]$} \\
\hline Functionalized-AuNPs/GCE & Amperometry & 0.14 & $8-6,000$ & 0.320 & {$[47]$} \\
\hline Au-PtNPs/Cys self-assembled/ITO & $\mathrm{CV}$ & 1 & $2-400$ & 0.250 & {$[48]$} \\
\hline AuNPs/PANI/GCE & Amperometry & 0.5 & $3-20,000$ & 0.300 & {$[49]$} \\
\hline AuNPs/silica/MWCNT/GCE & DPV & 220 & $1,000-5,000$ & 0.220 & {$[50]$} \\
\hline AuNPs/ßCD/graphene/GCE & SWV & 10 & $30-2,000$ & 0.222 & {$[51]$} \\
\hline $\mathrm{AuNPs} / \mathrm{TiO}_{2} / \mathrm{Ti}$ & DPV & 400 & $1,000-5,000$ & 0.350 & {$[41]$} \\
\hline AuSNPs/SNGC & DPV & 3.71 & $1.5-4,000$ & 0.104 & [9] \\
\hline MWCNT/GCE & SWV & 1.4 & $4.7-5,000$ & 0.315 & {$[52]$} \\
\hline PEDOT/Ni/Si/MCPE & DPV & 10 & $20-1,400$ & 0.030 & {$[53]$} \\
\hline $\mathrm{SGN} / \mathrm{NiPc}$ & DPV & 0.45 & $90-2,110$ & 0.300 & {$[54]$} \\
\hline polyXa/MWCNT/GCE & Amperometry & 0.1 & $1-1,520$ & 0.300 & {$[55]$} \\
\hline CTAB/ABPE & 2nd od LSV & 1 & $2-1,000$ & 0.284 & {$[56]$} \\
\hline $\mathrm{GCE}^{2}$ & DPV & 23.38 & $25-300$ & 0.010 & {$[57]$} \\
\hline $\mathrm{CeO}_{2} / \mathrm{GCE}$ & DPV & 1.50 & $5.0-1,000$ & 0.092 & {$[12]$} \\
\hline $\mathrm{PdNPs} / \mathrm{CeO}_{2} / \mathrm{GCE}$ & DPV & ---- & $100-600$ & -0.083 & {$[31]$} \\
\hline $\mathrm{CeO}_{2} / \mathrm{SNGC}^{3}$ & DPV & 1.59 & $1.5-4,000$ & 0.156 & This work \\
\hline $\mathrm{AuSNPs} / \mathrm{CeO}_{2} / \mathrm{SNGC}^{4}$ & DPV & 2.93 & $1.5-4,000$ & 0.140 & This work \\
\hline
\end{tabular}

$\beta$-Cyclodextrin ( $(\mathrm{CD})$ ), Ferrocene $(\mathrm{Fc})$, Cysteine (Cys), Polyaniline (PANI), Multi-walled carbon nanotubes (MWCNT), Sonogel-Carbon (SNGC), indium-tin-oxide (ITO), glassy-carbon electrode (GCE), poly(3,4-ethylenedioxythiophene) (PEDOT), microchannel plate electrode (MCPE), $\mathrm{SiO}_{2} / \mathrm{C}$-graphite matrices (SGN), phthalocyanine (Pc), poly(xanthurenic acid) (polyXa), cetyl trimethyl ammonium bromide film (CTAB), acetylyne black paste electrode (ABPE), Square Wave Voltammetry (SWV), 2nd order derivative Linear Sweep Voltammetry (2nd od LSV). ${ }^{1}$ The limits of detection are based on $\mathrm{S} / \mathrm{N}=3$ in all cases. ${ }^{2}$ Electro-chemically treated GCE in basic medium $(0.5 \mathrm{M} \mathrm{NaOH}) .{ }^{3}$ Corresponding to the $\mathrm{CeO}_{2}$ (10.0 $\mathrm{mg} \cdot \mathrm{mL}^{-1}$ )-modified SNGC electrode. ${ }^{4}$ Corresponding to the AuSNPs $/ \mathrm{CeO}_{2}(3.25 \% \mathrm{w} / \mathrm{w})$-modified SNGC electrode.

Table 5 shows the experimental results obtained for AA in the real sample measurements. The best recovery percentage values, calculated from three replicates, are shown in the table, as well as the configuration of the electrodes used for the measurements. According to the reference method employed, the concentration of AA is $1.24 \times 10^{-3} \mathrm{M}\left(218.0 \mathrm{mg} \cdot \mathrm{L}^{-1}\right)$ (the label of the real sample was $1.42 \times 10^{-3} \mathrm{M}\left(250.0 \mathrm{mg} \cdot \mathrm{L}^{-1}\right)$ as an average value $)$.

According to Table 5, in general, the results are remarkable and very similar in all cases. The error in the recovery percentage only goes beyond $5 \%$ in a few cases. After analyzing the recovery values, it can be concluded that $\mathrm{CeO}_{2-}$ and $\mathrm{AuSNPs} / \mathrm{CeO}_{2}$-modified $\mathrm{SNGC}$ electrodes give percentage values slightly higher and lower than $100 \%$, respectively. However, in general, the results obtained are rather good, with relative standard deviation (RSD) less than $6 \%$ in all cases, and precision ( $\mathrm{p}$-value $=0.05$ ) lower than 5\%. Besides, the AuSNPs/ $/ \mathrm{CeO}_{2}$-modified SNGC electrodes show lower standard deviation values in accordance to reproducibility and repeatability studies. According to scientific literature and as far as we know, this is the second time that the electrochemical determination of AA in baby juices 
is reported [9]. Other methods have been usually used: enzymatic, fluorimetric, chromatographic, but not exclusively electrochemical ones.

Table 5. Experimental results for the determination of the content of AA in apple juice for babies by using the standard addition method.

\begin{tabular}{|c|c|c|c|}
\hline Electrode & Measured $\left(\mathrm{mg} \cdot \mathrm{l}^{-1}\right)^{1} \pm \mathrm{SD}^{2}$ & Measured $\left(\times 10^{-3} \mathrm{M}\right) \pm \mathrm{SD}$ & Recovery $(\%) \pm \mathrm{SD}$ \\
\hline $\begin{array}{c}\mathrm{CeO}_{2}\left(0.25 \mathrm{mg} \cdot \mathrm{mL}^{-1}\right) \text {-modified } \\
\text { SNGC }\end{array}$ & $232.2 \pm 18.1$ & $1.251 \pm 0.05$ & $101.56 \pm 2.30$ \\
\hline $\begin{array}{c}\mathrm{CeO}_{2}\left(0.5 \mathrm{mg} \cdot \mathrm{mL}^{-1}\right) \text {-modified } \\
\text { SNGC }\end{array}$ & $220.4 \pm 9.4$ & $1.315 \pm 0.07$ & $106.22 \pm 1.77$ \\
\hline $\begin{array}{c}\mathrm{CeO}_{2}\left(0.75 \mathrm{mg} \cdot \mathrm{mL}^{-1}\right) \text {-modified } \\
\text { SNGC }\end{array}$ & $231.6 \pm 11.5$ & $1.294 \pm 0.04$ & $104.54 \pm 1.38$ \\
\hline $\begin{array}{c}\mathrm{CeO}_{2}\left(1.0 \mathrm{mg} \cdot \mathrm{mL}^{-1}\right) \text {-modified } \\
\mathrm{SNGC}\end{array}$ & $227.9 \pm 7.0$ & $1.239 \pm 0.05$ & $100.07 \pm 3.08$ \\
\hline $\begin{array}{c}\mathrm{CeO}_{2}\left(2.5 \mathrm{mg} \cdot \mathrm{mL}^{-1}\right) \text {-modified } \\
\mathrm{SNGC}\end{array}$ & $218.2 \pm 8.3$ & $1.336 \pm 0.02$ & $107.95 \pm 1.56$ \\
\hline $\begin{array}{c}\mathrm{CeO}_{2}\left(5.0 \mathrm{mg} \cdot \mathrm{mL}^{-1}\right) \text {-modified } \\
\text { SNGC }\end{array}$ & $235.3 \pm 3.4$ & $1.328 \pm 0.01$ & $107.3 \pm 0.43$ \\
\hline $\begin{array}{c}\mathrm{CeO}_{2}\left(7.5 \mathrm{mg} \cdot \mathrm{mL}^{-1}\right) \text {-modified } \\
\text { SNGC }\end{array}$ & $233.9 \pm 0.9$ & $1.287 \pm 0.03$ & $103.99 \pm 2.61$ \\
\hline $\begin{array}{c}\mathrm{CeO}_{2}\left(10.0 \mathrm{mg} \cdot \mathrm{mL}^{-1}\right) \text {-modified } \\
\mathrm{SNGC}\end{array}$ & $226.7 \pm 5.7$ & $1.277 \pm 0.01$ & $103.17 \pm 0.67$ \\
\hline $\begin{array}{c}\text { AuSNPs } / \mathrm{CeO}_{2}(25 \% \mathrm{w} / \mathrm{w})- \\
\text { modified SNGC }\end{array}$ & $224.9 \pm 1.5$ & $1.242 \pm 0.04$ & $100.31 \pm 2.63$ \\
\hline $\begin{array}{c}\mathrm{AuSNPs} / \mathrm{CeO}_{2}(17.25 \% \mathrm{w} / \mathrm{w})- \\
\text { modified SNGC }\end{array}$ & $218.7 \pm 7.7$ & $1.188 \pm 0.04$ & $96.01 \pm 1.26$ \\
\hline $\begin{array}{c}\text { AuSNPs } / \mathrm{CeO}_{2}(12.5 \% \mathrm{w} / \mathrm{w})- \\
\text { modified SNGC }\end{array}$ & $209.3 \pm 7.1$ & $1.225 \pm 0.04$ & $98.96 \pm 2.08$ \\
\hline $\begin{array}{c}\mathrm{AuSNPs} / \mathrm{CeO}_{2}(5 \% \mathrm{w} / \mathrm{w})- \\
\text { modified SNGC }\end{array}$ & $215.7 \pm 7.2$ & $1.156 \pm 0.03$ & $93.41 \pm 2.00$ \\
\hline $\begin{array}{c}\mathrm{AuSNPs} / \mathrm{CeO}_{2}(3.25 \% \mathrm{w} / \mathrm{w})- \\
\mathrm{CeO}_{2} \text {-modified } \mathrm{SNGC}\end{array}$ & $203.6 \pm 4.4$ & $1.093 \pm 0.003$ & $88.76 \pm 0.01$ \\
\hline $\begin{array}{c}\mathrm{AuSNPs} / \mathrm{CeO}_{2}(2.5 \% \mathrm{w} / \mathrm{w})- \\
\mathrm{CeO}_{2} \text {-modified } \mathrm{SNGC}\end{array}$ & $193.5 \pm 0.03$ & $1.202 \pm 0.03$ & $97.09 \pm 2.37$ \\
\hline
\end{tabular}

\subsection{Structural Characterization of $\mathrm{CeO}_{2}$ - and $\mathrm{AuSNPS} / \mathrm{CeO}_{2}$-Modified $\mathrm{SNGC}$ Electrodes}

The structural characterization of the surface of the SNGC electrodes at the different configurations was carried out by employing several instrumental techniques: SEM and EDS. As in the electrochemical studies, the configurations tested for the electrodes were: one bare, eight different concentrations of $\mathrm{CeO}_{2}$-modified and six different proportions of AuSNPs/CeO $\mathrm{Ce}_{2}$-modified SNGC electrodes. For each sample the corresponding electrode used and the electrode not used were analyzed. 


\subsubsection{Scanning Electron Microscopy and Energy Dispersive X-ray Spectroscopy}

For each sample, the SEM and EDS studies were performed on the same equipment and at the same time, as it was mentioned in the experimental section. As SEM studies were carried out at low vacuum, it was not necessary a previous step of coating the samples with gold. The micrographs were taken at $20 \mathrm{kV}$ in all cases and at different magnifications: $90 \times, 160 \times, 300 \times$ and $600 \times$. Higher magnifications were used to observe some interesting details, mainly when studying the presence of $\mathrm{CeO}_{2}$ and AuSNPs on the surface of the electrodes. The main conclusions that can be obtained after applying this technique are summarized as follows:

1. The use of the voltammetric device, either bare or modified, causes small erosion of the electrode surface in the form of holes and fissures, and a greater separation between the composite material and the wall of the glass-capillary tubes. This erosion is mainly produced during the electrochemical polarization or activation of the SNGC electrodes in a $0.05 \mathrm{M}$ $\mathrm{H}_{2} \mathrm{SO}_{4}$ solution $(\mathrm{pH} \simeq 1)$. When the electrode has not been used, this erosion is negligible. Moreover, during the gelification step no significant volume contraction is appreciated what is very important for the mechanical stability of the electrodes. These results are consistent with literature [32]. In all cases, EDS spectra confirm the presence of Si, O and C: the first two ones corresponding to the Sonogel matrix and $\mathrm{C}$ as the massive modifier.

2. Concerning the $\mathrm{CeO}_{2}$-modified electrochemical sensors developed throughout this work, the $\mathrm{CeO}_{2}$ nanoparticles remain attached to the electrode surface in the form of a film even after many measurements (with more or less thickness according to the concentration of the nanomaterial) and without the presence of some protective agent or membrane (excepting for the $\mathrm{CeO}_{2}\left(7.5 \mathrm{mg} \cdot \mathrm{mL}^{-1}\right)$-modified electrode, which may have suffered from other problems, mainly during the drying step). However, with respect to the AuSNPs/ $\mathrm{CeO}_{2}$-modified electrodes, the situation turns to be the opposite: most part of the film seems to fall down due to its weight, presence of ionic species coming from the AuSNPs synthesis solution and other unknown factors.

3. The presence of $\mathrm{CeO}_{2}$ or $\mathrm{AuSNPs} / \mathrm{CeO}_{2}$ homogeneous film could be directly related to the electrochemical performances of the devices. Moreover, this might confirms that the electrocatalytic processes suffered by the different analytes take place preferentially on the nanoparticles surface.

4. Finally, the backscattered detector is a very powerful tool to help us to identify different phases according to the qualitative chemical composition of the electrode surface.

Figure 9 shows several SEM micrographs and example of EDS spectra corresponding to two different configurations of the $\mathrm{CeO}_{2}$-modified SNGC electrodes, used and not used. The micrographs correspond to the $\mathrm{CeO}_{2}\left(0.75 \mathrm{mg} \cdot \mathrm{mL}^{-1}\right)$ - and $\mathrm{CeO}_{2}\left(10.0 \mathrm{mg} \cdot \mathrm{mL}^{-1}\right)$-modified $\mathrm{SNGC}$ electrodes, (A) used and (B) not used, for the first one, and (C) used and (D) not used, for the second one. As it can be seen, the surface of the SNGC electrodes is covered by a white film of $\mathrm{CeO}_{2}$ nanoparticles that appears in dark gray in micrographs (C) and (D), taken with a backscattered electron detector. When using this kind of detector it is very simple to identify different phases based on qualitative chemical composition of the electrode surface, especially when there is much difference in the atomic number, 
i.e., SNGC matrix and glass of the capillary tube (light gray) and $\mathrm{CeO}_{2}$ nanoparticles. According to this, from Figure $9(\mathrm{C}, \mathrm{D}), \mathrm{CeO}_{2}$ nanoparticle film can be distinguished from the SNGC matrix and information about how they coat the electrode surface can be extracted. In both devices, homogeneous film of cerium oxide nanoparticles can be observed, excepting for some small zones (dark gray in secondary electron detector and light gray in backscattered detector) corresponding to the Sonogel-Carbon matrix, although it could be assumed that small nanoparticles and not big aggregates still remain in these zones. However, it is obvious that the thickness of the film decrease when using the electrochemical device and that this fact might affect its performance. Nevertheless, from the results obtained, it is not possible to affirm categorically this relationship, mainly after testing that the electrocatalytic activity of these devices can be reproduced and repeated after many uses with most of the modified SNGC sensors, as we have seen previously from the CV and DPV studies. The fall can be also explained in terms of the mechanical fissures appearing on the film surface during the drying step, as observed in micrograph (D). The presence of $\mathrm{CeO}_{2}$ is corroborated by the EDS spectrum (Figure 9(E)), as well as, the components of the SNGC matrix: Si, C and O.

Figure 9. SEM micrographs and example of EDS corresponding to different configurations of the SNGC electrodes used and not used: $\mathrm{CeO}_{2}\left(0.75 \mathrm{mg} \cdot \mathrm{mL}^{-1}\right)$-modified SNGC electrode (A) used and (B) not used, both obtained with the secondary electron detector; $\mathrm{CeO}_{2}\left(10.0 \mathrm{mg} \cdot \mathrm{mL}^{-1}\right)$-modified SNGC electrode (C) used and (D) not used, both obtained with the backscattered electron detector; (E) X-ray EDS corresponding to the $\mathrm{CeO}_{2}$ nanoparticles film deposited on the surface of a SNGC electrode. All the micrographs were obtained at the magnification of $90 \times$ and operating in the range of $24-30 \mathrm{kV}$.
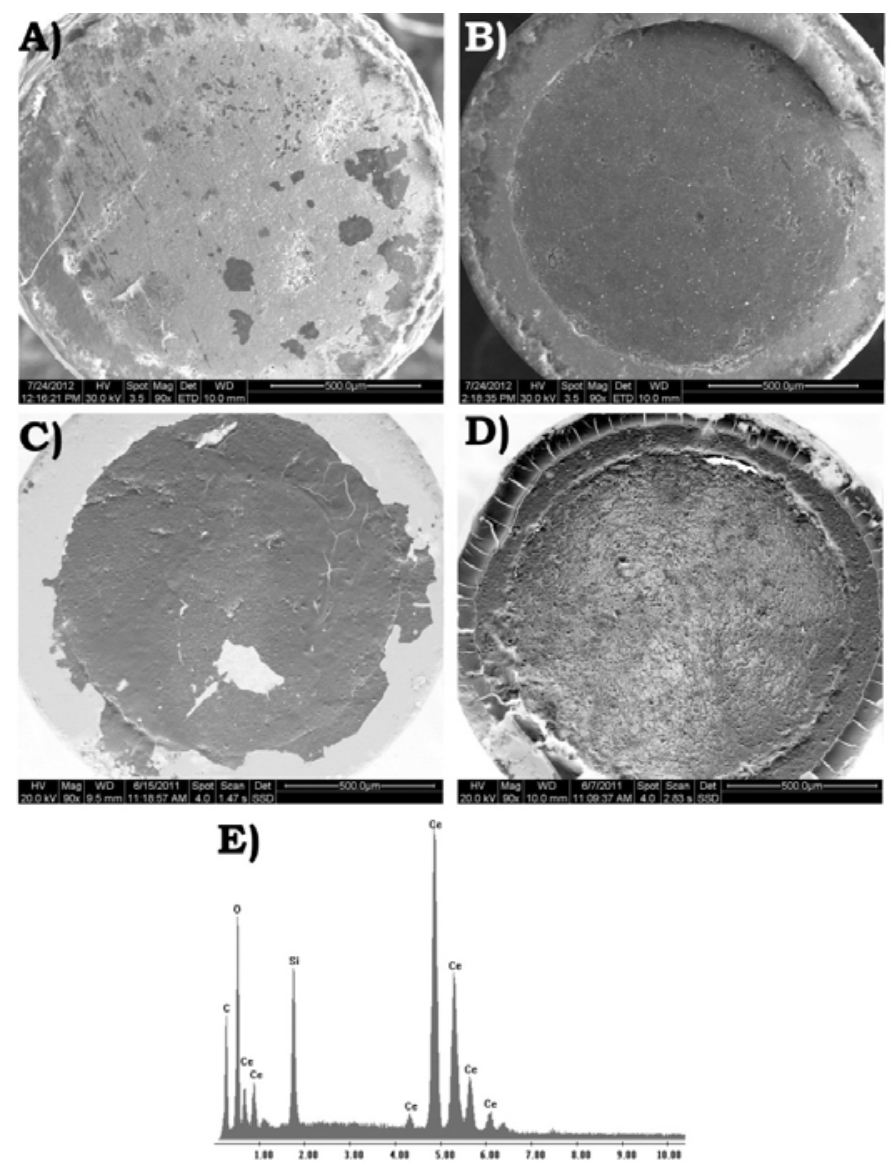
Figure 10 shows the SEM micrographs and an example of the EDS spectra of two different configurations of the AuSNPs/ $\mathrm{CeO}_{2}$-modified SNGC electrodes, used and not used. The micrographs correspond to the AuSNPs $/ \mathrm{CeO}_{2}(25 \% \mathrm{w} / \mathrm{w})-$ and $\mathrm{AuSNPs} / \mathrm{CeO}_{2}(2.5 \% \mathrm{w} / \mathrm{w})$-modified SNGC electrodes, (A) used and (B) not used, for the first one, and (C) used and (D) not used, for the second one. As in the previous SEM micrographs, (C) and (D) were taken with a backscattered electron detector. From the figure, it can be concluded that the use of the electrochemical devices reduces significantly the AuSNPs $/ \mathrm{CeO}_{2}$ film thickness in both electrodes, being more remarkable for higher proportions of AuSNPs $/ \mathrm{CeO}_{2}$. Despite this, it seems that the nanocomposite film on the electrodes surface continues being homogeneous after their use.

Figure 10. SEM micrographs and example of EDS corresponding to different configurations of the SNGC electrodes used and not used: AuSNPs $/ \mathrm{CeO}_{2}(25 \% \mathrm{w} / \mathrm{w})-$ modified SNGC electrode (A) used and (B) not used, both obtained with the secondary electron detector; AuSNPs/ $\mathrm{CeO}_{2}(2.5 \% \mathrm{w} / \mathrm{w})$-modified SNGC electrode (C) used and (D) not used, both obtained with the backscattered electron detector; (E) X-ray EDS corresponding to the AuSNPs $/ \mathrm{CeO}_{2}$ nanocomposite film deposited on the surface of a SNGC electrode. All the micrographs were obtained at the magnification of $90 \times$ and operating in the range of $24-30 \mathrm{kV}$.
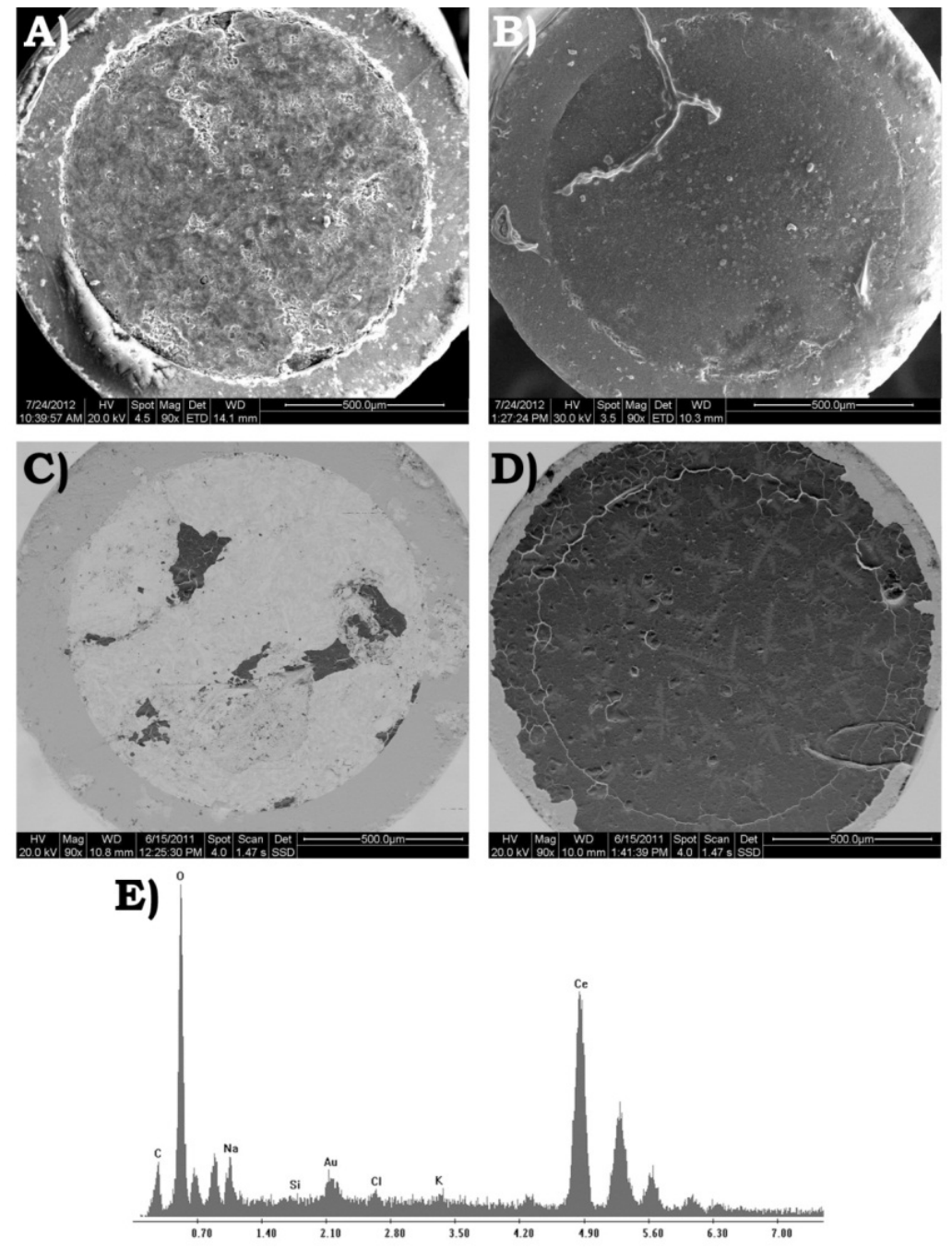
As stated formerly, the AuSNPs $/ \mathrm{CeO}_{2}$ film is heavier than the corresponding $\mathrm{CeO}_{2}$ film alone. Hence, the possibility of the film fall is higher in this case. Again, the EDS spectrum can be used to corroborate the presence of $\mathrm{CeO}_{2}$ and AuSNPs on the electrode surface (Figure 10(E)). The components of the SNGC matrix are also displayed (Si and C peaks are very small due to the EDS spot was focused on the film surface, with no much depth), and $\mathrm{Na}, \mathrm{K}$ and $\mathrm{Cl}$ appear as new constituting elements. The origin of the last three ones can be attributed to the Au colloidal solution ( $\mathrm{K}$ and $\mathrm{Cl}$ from $\mathrm{KAuCl}_{4}$, gold precursor, and $\mathrm{Na}$ from sodium citrate, reducing agent).

\section{Conclusions}

In this work, a complete study of the electrocatalytic activity of $\mathrm{CeO}_{2}$ nanoparticles and AuSNPs $/ \mathrm{CeO}_{2}$ nanocomposite, deposited on the surface of the Sonogel-Carbon material used as supporting electrode, was accomplished. The modification of these electrochemical devices was done by simply drop-casting both nanomaterials on the electrode surface.

Different instrumental techniques were used to structurally characterize both the nanoparticles and the electrochemical devices built with them. These techniques provided us information about the bond of the $\mathrm{CeO}_{2}$ nanoparticles and the AuSNPs $/ \mathrm{CeO}_{2}$ nanocomposite on the electrode surface: this bond seems to be strong enough to maintain them attached to the electrode surface, even after many measurements and without the presence of any protective agent or membrane.

$\mathrm{CeO}_{2}$ - and AuSNPs/ $\mathrm{CeO}_{2}$-modified SNGC electrodes were electrochemically characterized by $\mathrm{CV}$ and DPV. The electrocatalytic activity of AA, used as a benchmark analyte, was tested, obtaining in general good results. The main advantages given by the electrochemical devices described here can be summarized as follows: (i) AuNPs used here were synthesized by following a fast and green route and the procedure to "decorate" $\mathrm{CeO}_{2}$ nanoparticles with AuSNPs, only dependent of the stirring time, was very simple, this process being controlled by UV-vis spectroscopy; (ii) the final configuration of the sensing devices is much simpler and offers similar results, or even better in some cases, than most reported in literature; and (iii) it has also been demonstrated that most of the electrodes are rather sensitive, with a relatively high linear range of concentration, showing high reproducibility and repeatability when comparing with other AA sensors, even when part of the nanomaterial-based film is lost because of the continued use of the electrochemical sensors.

The electrochemical devices were also tested for the determination of AA in commercial apple juice for babies, obtaining comparable results with respect to the reference technique. Moreover, as far as we know, this is the second time that the electrochemical determination of AA in baby juices is reported (other methods have been used: enzymatic, chromatographic, but not electrochemical ones). This research suggests that the modified electrodes presented here can be a very promising voltammetric sensor for the determination of AA in real samples.

\section{Acknowledgments}

Financial supports from the Junta de Andalucía (FQM-249, P08-FQM-04006), Ministerio de Ciencia e Innovación of Spain and FEDER founds (CTQ2010-19058/BQU) are acknowledged. We also thank the European Commission Education and Culture DG for supporting Mohamed Yahia Marei Abdelrahim's 
and Stephen Rathinaraj Benjamin's graduate research and studies (Erasmus Mundus Master in Quality in Analytical Laboratories-EMQAL) through an Erasmus Mundus studentship.

\section{References}

1. Schmid, G.; Corain, B. Nanoparticulated gold: Syntheses, structures, electronics, and reactivities. Eur. J. Inorg. Chem. 2003, 17, 3081-3098.

2. Brown, L.O.; Hutchison, J.E. Formation and electron diffraction studies of ordered 2-d and 3-d superlattices of amine-stabilized gold nanocrystals. J. Phys. Chem. B 2001, 105, 8911-8916.

3. Whetten, R.L.; Khoury, J.T.; Alvarez, M.M.; Murthy, S.; Vezmar, I.; Wang, Z.L.; Stephens, P.W.; Cleveland, C.L.; Luedtke, W.D.; Landman, U. Nanocrystal gold molecules. Adv. Mater. 1996, 8, 428-433.

4. Patra, C.R.; Bhattacharya, R.; Mukhopadhyay, D.; Mukherjee, P. Fabrication of gold nanoparticles for targeted therapy in pancreatic cancer. Adv. Drug Deliver. Rev. 2010, 62, 346-361.

5. Qin, X.; Wang, H.; Wang, X.; Miao, Z.; Chen, L.; Zhao, W.; Shan, M.; Chen Q. Amperometric biosensors based on gold nanoparticles-decorated multiwalled carbon nanotubes-poly (diallyldimethylammonium chloride) biocomposite for the determination of choline. Sens. Actuators B Chem. 2010, 147, 593-598.

6. Guo, S.; Wang, E. Synthesis and electrochemical applications of gold nanoparticles. Anal. Chim. Acta 2007, 598, 181-192.

7. Cubillana-Aguilera, L.M.; Palacios-Santander, J.M.; Franco-Romano, M.; Gil-Montero, M.L.A.; Naranjo-Rodríguez, I.; de Hidalgo-Hidalgo Cisneros, J.L. Síntesis Verde (Ecológica) de Sononanopartículas de Oro. ES2364914, Spain, 2010.

8. Cubillana-Aguilera, L.M.; Franco-Romano, M.; Gil, M.L.A.; Naranjo-Rodríguez, I.; de Hidalgo-Hidalgo Cisneros, J.L.; Palacios-Santander, J.M. New, fast and green procedure for the synthesis of gold nanoparticles based on sonocatalysis. Ultrason. Sonochem. 2011, 18, 789-794.

9. Ajaero, C.; Abdelrahim, M.Y.M.; Palacios-Santander J.M.; Gil, M.L.A; Naranjo-Rodríguez, I.; de Hidalgo-Hidalgo Cisneros, J.L.; Cubillana-Aguilera, L.M. Comparative study of the electrocatalytic activity of different types of gold nanoparticles using sonogel-carbon material as supporting electrode. Sens. Actuators B Chem. 2012, 171-172, 1244-1256.

10. Panizza, M.; Cerisola, G. Direct and mediated anodic oxidation of organic pollutants. Chem. Rev. 2009, 109, 6541-1569.

11. Dong, S.; Kuwana, T. Activation of glassy carbon electrodes by dispersed metal oxide particles. I. Ascorbic acid oxidation. J. Electrochem. Soc. 1984, 134, 813-819.

12. Wei, Y.; Li, M.; Jiao, S.; Huang, Q.; Wang, G.; Fang, B. Fabrication of $\mathrm{CeO}_{2}$ nanoparticles modified glassy carbon electrode and its application for electrochemical determination of UA and AA simultaneously. Electrochim. Acta 2006, 52, 766-772.

13. Cox, J.A.R.K. Jaworski, P.J. Electroanalysis with electrodes modified by inorganic films. Electroanalysis 1991, 3, 869-877.

14. Casella, I.G.; Gatta, M; Contursi, M. Oxidation of sugar acids on polycrystalline platinum and gold electrodes modified with adsorbed bismuth oxide adlayers. J. Electroanal. Chem. 2004, 561, 103-111. 
15. Heras, M.A.; Lupu, S.; Pigani, L.; Pirvu, C.; Seeber, R.; Terzi, F.; Zanardi, C. A poly (3,4-ethylenedioxythiophene)-poly (styrene sulphonate) composite electrode coating in the electrooxidation of phenol. Electrochim. Acta 2005, 50, 1685-1691.

16. Pigani, L.; Musiani, M.; Pirvu, C.; Terzi, F.; Zanardi, C.; Seeber, R. Electro-oxidation of chlorophenols on poly (3,4-ethylenedioxythiophene)-poly (styrene sulphonate) composite electrode. Electrochim. Acta 2007, 52, 1910-1918.

17. Kosmulski, M. Compilation of PZC and IEP of sparingly soluble metal oxides and hydroxides from literature. Adv. Colloid Interface. 2009, 152, 14-25.

18. Tschöpe, A.; Sommer, E.; Birringer, R. Grain size-dependent electrical conductivity of polycrystalline cerium oxide. I. Experiments. Solid State Ionics 2001, 139, 255-265.

19. Nelson, A.E.; Schulz, K.H. Surface chemistry and microstructural analysis of CexZr1-xO2-y model catalyst surfaces. Appl. Surf. Sci. 2003, 210, 206-221.

20. Yahiro, H.; Bada, Y.; Eguchi, K.; Arai, H. High temperature fuel cell with ceria-yttria solid electrolyte. J. Electrochem. Soc. 1988, 135, 2077-2080.

21. Campos, C.L.; Roldan, C.; Aponte, M.; Ishikawa, Y.; Cabrera, C.R. Preparation and methanol oxidation catalysis of Pt-CeO 2 electrode. J. Electroanal. Chem. 2005, 581, 206-215.

22. Guo, J.W.; Zhao, T.S.; Prabhuram, J.; Chen, R.; Wong, C.W. Development of PtRu-CeO 2/C anode electrocatalyst for direct methanol fuel cells. J. Pow. Source. 2006, 156, 345-354.

23 Wang, J.; Xi, J.; Bai, Y.; Shen, Y.; Sun, J.; Chen, L., Zhu, W.; Qiu, X. Structural designing of Pt-CeO $\mathrm{C}_{2} / \mathrm{CNT}$ s for methanol electro-oxidation. J. Pow. Source. 2007, 164, 555-560.

24. Wei, Y.; Li, M.G.; Fang, B. Fabrication of $\mathrm{CeO}_{2}$ nanoparticle modified glassy carbon electrode for ultrasensitive determination of trace amounts of uric acid in urine. Chin. J. Chem. 2007, 25, $1622-1626$.

25. Zhang, D.E.; Chen, A.M.; Wang, M.Y.; Gong, J.Y.; Zhang, X.B.; Li, S.Z.; Han, G.Q.; Ying, A.L.; Tong, Z.W. Solvothermal preparation of $\mathrm{CeO}_{2}$ nanocubes and their catalytic properties. Funct. Mater. Lett. 2011, 4, 97-100.

26. Njagi, J.; Chernov, M.M.; Leiter, J.C.; Andreescu, S. Amperometric detection of dopamine in vivo with an enzyme based carbon fiber microbiosensor. Anal. Chem. 2010, 82, 989-996.

27. Ansari, A.A.; Sumana, G.; Pandey, M.K.; Malhotra, B.D. Sol-gel-derived titanium oxide-cerium oxide biocompatible nanocomposite film for urea sensor. J. Mater. Res. 2009, 24, 1667-1673.

28. Kumar, S.A.; Cheng, H.W.; Chen, S.M.; Wang, S.F. Preparation and characterization of copper nanoparticles/zinc oxide composite modified electrode and its application to glucose sensing. Mater. Sci. Eng. C 2010, 30, 86-91.

29. Zang, J.; Li, C.M.; Cui, X.; Wang, J.; Sun, X.; Chang, H.D.; Sun, Q. Tailoring zinc oxide nanowires for high performance amperometric glucose sensor. Electroanalysis 2007, 19, 1008-1014.

30. Zhou, W.; Zhu, J.; Cheng, C.; Liu, J.; Yang, H.; Cong, C.; Guan, C.; Jia, X.; Fan, H.J.; Yan, Q.; Li, C.M.; Yu, T. A general strategy toward graphene@metal oxide core-shell nanostructures for high-performance lithium storage. Energy Environ. Sci. 2011, 4, 4954-4961.

31. Qu, F.; Sun, H.; Zhang, S.; You, J.; Yang M. Electrochemical sensing platform based on palladium modified ceria nanoparticles. Electrochim. Acta 2012, 61, 173-178.

32. Cordero-Rando, M.M.; de Hidalgo-Hidalgo Cisneros, J.L.; Blanco, E.; Naranjo Rodríguez, I. The sonogel-carbon electrode as a sol-gel graphite-based electrode. Anal. Chem. 2002, 74, 2423-2427. 
33. Hidalgo-Hidalgo-de-Cisneros, J.L.; Cordero-Rando, M.M.; Naranjo-Rodríguez, I.; Blanco-Ollero, E.; Esquivias-Fedriani, L. ES2195715, Spain, 2001.

34. Sun, K., Qiu, J.; Liu, J.; Miao, Y. Preparation and characterization of gold nanoparticles using ascorbic acid as reducing agent in reverse micelles. J. Mater. Sci. 2009, 44, 754-758.

35. Bard, A.J.; Faulkner, L.R. Electrochemical Methods: Fundamentals and Applications, 2nd ed.; John Wiley and Sons: New York, NY,USA, 2001.

36. Wang, M.; Xu, X.; Gao, J. Voltammetric studies of a novel bicopper complex modified glassy carbon electrode for the simultaneous determination of dopamine and ascorbic acid. J. Appl. Electrochem. 2007, 37, 705-710.

37. Salimi, A.; Alizadeh, V.; Hadadzadeh, H. Renewable surface sol-gel derived carbon ceramic electrode modified with copper complex and its application as an amperometric sensor for bromate detection. Electroanalysis 2004, 16, 1984-1991.

38. Pournaghi-Azar, M.H.; Razmi-Nerbin, H. Electrocatalytic characteristics of ascorbic acid oxidation at nickel plated aluminum electrodes modified with nickel pentacyanonitrosylferrate films. J. Electroanal. Chem. 2000, 488, 17-24.

39. Ardakani, M.M.; Akrami, Z.; Kazemian, H.; Zare, H.R. J. Electroanal. Chem. 2006, 586, 31-38.

40. Fernandez, L.; Carrero, H. Electrochemical evaluation of ferrocene carboxylic acids confined on surfactant-clay modified glassy carbon electrodes: Oxidation of ascorbic acid and uric acid. Electrochim. Acta 2005, 50, 1233-1240.

41. Hosseini, M.G.; Faraji, M.; Momeni, M.M. Application of titanium oxide nanotube films containing gold nanoparticles for the electroanalytical determination of ascorbic acid. Thin Solid Films 2011, 519, 3457-3461.

42. Cubillana-Aguilera, L.M.; Palacios-Santander, J.M.; Naranjo-Rodríguez, I.; de Hidalgo-Hidalgo Cisneros, J.L. Study of the influence of the graphite powder particle size on the structure of the sonogel-carbon materials. J. Sol. Gel. Sci. Technol. 2006, 40, 55-64.

43. Keating, C.D.; Musick, M.D.; Keefe, M.H.; Natan, M.J. Kinetics and thermodynamics of Au colloid monolayer self-assembly undergraduate experiments in surface and nanomaterials chemistry. J. Chem. Educ. 1999, 76, 949-955.

44. Ferreira, S.L.C.; Bruns, R.E.; Ferreira, H.S.; Matos, G.D.; David, J.M.; Brandao, G.C.; da Silva, E.G.P.; Portugal, L.A.; dos Reis, P.S.; Souza, A.S.; et al. Box-Behnken design: An alternative for the optimization of analytical methods. Anal. Chim. Acta 2007, 597, 179-186.

45. Miller, J.C.; Miller, J.N. Estadística Para Química Analítica; Addison-Wesley Iberoamericana: Wilmington, DC, USA, 1993; pp. 96-98.

46. Zuo, F.; Luo, C.; Zheng, Z.; Ding, X.; Peng, Y. Supramolecular assembly of $\beta$-cyclodextrin-capped gold nanoparticles on ferrocene-functionalized ITO surface for enhanced voltammetric analysis of ascorbic acid. Electroanalysis 2008, 20, 894-899.

47. Shi, H.; Xu, Y.; Wang, Y.; Song, W. Assembly of ferrocenylhexanethiol functionalized gold nanoparticles for ascorbic acid determination. Microchim. Acta 2010, 171, 81-89.

48. Lin, Y.; Hu, Y.; Long, Y.; Di, J. Determination of ascorbic acid using an electrode modified with cysteine self-assembled gold-platinum nanoparticles. Microchim. Acta 2011, 175, 259-264. 
49. Xu, Q.; Leng, J.; Li, H.B.; Lu, G.J.; Wang, Y.; Hu, X.Y. The preparation of polyaniline/gold nanocomposites by self-assembly and their electrochemical applications. React. Funct. Polym. 2010, 70, 663-668.

50. Ragupathy, D.; Iyengar Gopalan, A.; Lee, K.-P. Electrocatalytic oxidation and determination of ascorbic acid in the presence of dopamine at multiwalled carbon nanotube-silica network-gold nanoparticles based nanohybrid modified electrode. Sens. Actuators B Chem. 2010, 143, 696-703.

51. Tian, X.; Cheng, C.; Yuan, H.; Du, J.; Xiao, D.; Xie, S.; Choi, M.M.F. Simultaneous determination of L-ascorbic acid, dopamine and uric acid with gold nanoparticles- $\beta$-cyclodextringraphene-modified electrode by square wave voltammetry. Talanta 2012, 93, 79-85.

52. Kumar, S.; Vicente-Beckett, V. Glassy carbon electrodes modified with multiwalled carbon nanotubes for the determination of ascorbic acid by square-wave voltammetry. Beilstein. J. Nanotechnol. 2013, 3, 388-396.

53. Yu, S.; Luo, C.; Wang, L.; Peng, H.; Zhua, Z. Poly(3,4-ethylenedioxythiophene)-modified $\mathrm{Ni} /$ silicon microchannel plate electrode for the simultaneous determination of ascorbic acid, dopamine and uric acid. Analyst 2013, 38, 1149-1155.

54. Barrosa, S.B.A.; Rahim, A.; Tanaka, A.A.; Arenas, L.T.; Landers, R.; Gushikem, Y. In situ immobilization of nickel(II) phthalocyanine on mesoporous $\mathrm{SiO}_{2} / \mathrm{C}$ carbon ceramic matrices prepared by the sol-gel method: Use in the simultaneous voltammetric determination of ascorbic acid and dopamine. Electrochim. Acta 2013, 87, 140-147.

55. Lin, K.-C.; Yeh, P.-C.; Chen, S.-M. Electrochemical determination of ascorbic acid using poly(xanthurenic acid) and multi-walled carbon nanotubes, Int. J. Electrochem. Sci. 2012, 7, 12752-12763.

56. Deng, P.; Xu, Z.; Feng, Y. Highly sensitive and simultaneous determination of ascorbic acid and rutin at an acetylene black paste electrode coated with cetyltrimethyl ammonium bromide film. J. Electroanal. Chem. 2012, 683, 47-54.

57. Temoçin, Z. Modification of glassy carbon electrode in basic medium by electrochemical treatment for simultaneous determination of dopamine, ascorbic acid and uric acid. Sens. Actuators B Chem. 2013, 176, 796-802.

(C) 2013 by the authors; licensee MDPI, Basel, Switzerland. This article is an open access article distributed under the terms and conditions of the Creative Commons Attribution license (http://creativecommons.org/licenses/by/3.0/). 